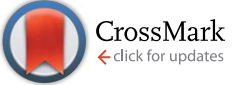

Cite this: RSC Adv., 2017, 7, 4960
Received 29th November 2016 Accepted 27th December 2016 DOI: $10.1039 / c 6 r a 27496 j$

www.rsc.org/advances

\section{Isocyano compounds newly recognized in photochemical reaction of thiazole: matrix- isolation FT-IR and theoretical studies $\uparrow$}

\begin{abstract}
Jun Miyazaki, ${ }^{\text {ab }}$ Hiroshi Takiyama ${ }^{\mathrm{b}}$ and Munetaka Nakata*c
UV-induced photoreactions of thiazole isolated in low-temperature argon matrices have been investigated by a joint use of infrared spectroscopy and density-functional-theory calculations. Photoproducts have been identified by comparison of the observed infrared spectra with the corresponding calculated spectral patterns, leading to the conclusion that undetected open-chain molecules, syn-2isocyanoethenethiol $(\mathrm{C} \equiv \mathrm{N}-\mathrm{CH}=\mathrm{CH}-\mathrm{SH})$ and 2-isocyanothiirane, are initially produced by cleavage of the $\mathrm{CS}-\mathrm{CN}$ bond with hydrogen-atom migration, when the matrix samples are exposed to UV radiation coming from a super high-pressure mercury lamp for $3 \mathrm{~min}$. In the secondary photolysis, syn-2isocyanoethenethiol and 2-isocyanothiirane change to another unknown molecule, 2isocyanoethanethial $\left(\mathrm{C} \equiv \mathrm{N}-\mathrm{CH}_{2}-\mathrm{CH}=\mathrm{S}\right)$, by hydrogen-atom migration with generation of the $\mathrm{C}=\mathrm{S}$ double bond. These photoreaction pathways are supported by kinetic analysis of the absorbance changes of IR bands against irradiation time. We have also found that $\mathrm{HC} \equiv \mathrm{N}$ and the ${ }^{\circ} \mathrm{CH}=\mathrm{CH}-\mathrm{S}^{*}$ biradical are photodecomposed from thiazole by cleavage of the $\mathrm{CN}-\mathrm{CC}$ bond following the cleavage of the $\mathrm{CS}-\mathrm{CN}$ bond, where the hydrogen atom on the center carbon atom of ${ }^{\circ} \mathrm{CH}=\mathrm{CH}-\mathrm{S}^{\cdot}$ immediately migrates to the end carbon atom to form $\mathrm{CH}_{2}=\mathrm{C}=\mathrm{S}$ or to the sulfur atom to form $\mathrm{HC} \equiv \mathrm{C}-\mathrm{SH}$. In addition, weak bands of the species of interest in astrophysics and astrochemistry such as $\mathrm{HC} \equiv \mathrm{CH}$, $\mathrm{N} \equiv \mathrm{C}-\mathrm{SH}, \mathrm{HN}=\mathrm{C}=\mathrm{S}, \mathrm{HC} \equiv \mathrm{NS}$, and the ${ }^{\circ} \mathrm{CN}$ radical are detected, but the photoconversion from thiazole to isothiazole or Dewar thiazole is not found. The ring-opening photoreaction, photoisomerization and photodecomposition pathways of thiazole isolated in low-temperature argon matrices are discussed comprehensively.
\end{abstract}

\section{Introduction}

Thiazole (1) and isothiazole $\left(\mathbf{1}^{\prime}\right)$ are fundamental heterocyclic compounds with a five-membered ring including one nitrogen and one sulfur atom (Fig. 1). The thiazole ring is one of the components of natural products such as thiamine (Vitamin B1) and D-firefly luciferin, and structurally diverse alkaloids

${ }^{a}$ Faculty of Pharmaceutical Sciences, Hokuriku University, Ho-3, Kanagawa-machi, Kanazawa, Ishikawa 920-1181, Japan.E-mail: j-miyazaki@hokuriku-u.ac.jp

${ }^{b}$ Department of Chemical Engineering, Tokyo University of Agriculture and Technology, 2-24-16 Naka-cho, Koganei, Tokyo 184-8588, Japan

${ }^{c}$ Graduate School of BASE (Bio-Applications and Systems Engineering), Tokyo University of Agriculture and Technology, 2-24-16 Naka-cho, Koganei, Tokyo 1848588, Japan. E-mail: necom816@cc.tuat.ac.jp

$\dagger$ Electronic supplementary information (ESI) available: Tables listing observed wavenumbers and IR intensities of thiazole (1) isolated in solid argon matrices with references, and calculated wavenumbers and IR intensities of 2-isocyanoethenethiol (2), 2-isocyanoethenethial (3), 2-isocyanothiirane (4), (methyleneamino)-ethenethione (5), $N$-ethynylthiformamide (6), Dewar thiazole, and 2-cyanothiirane obtained at the DFT/UB3LYP/aug-cc-pVTZ level, and a figure showing calculated potential energy around the $\mathrm{C}-\mathrm{NH}-\mathrm{CH}=\mathrm{S}$ dihedral angle of $\mathrm{N}$-ethynylthioformamide (6)obtained by the one-step optimization at an interval of $15^{\circ}$. See DOI: $10.1039 / \mathrm{c} 6 \mathrm{ra} 27496 \mathrm{j}$ containing thiazole subunits are widely distributed in terrestrial and marine organisms and microorganisms., ${ }^{1,2}$ Thiazole derivatives in various natural and synthetic products, for example Bleomycin, with a wide range of pharmacological activities ${ }^{1-3}$ are known to be useful for human health.

In astrochemical and astrophysical studies, UV photochemistry of heterocyclic molecules, which have yet to be detected in the interstellar medium (ISM), gives important information on small photofragments composed of $\mathrm{H}, \mathrm{C}, \mathrm{N}, \mathrm{O}$, and $\mathrm{S}$ because they are exposed to the strong UV radiation. In addition, the

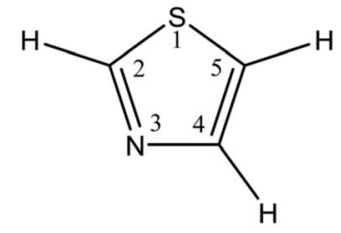

(1)

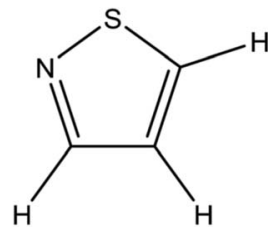

(1')
Fig. 1 Structures of thiazole (1) and isothiazole ( $\left.1^{\prime}\right)$, and numbering of atoms. 
heterocyclic compounds are interested in astrobiology as the origins of $\mathrm{S}$ and $\mathrm{N}$ involved in biological materials. ${ }^{4}$ Indeed, 2aminothiazole $^{5}$ and 2-aminooxazole ${ }^{6}$ have been recently considered as important nucleotide precursors, implying that azole derivatives have potentials of prebiotic molecules. Since they have attractive electronically excited states due to calcogens $(\mathrm{O}, \mathrm{S}$, and $\mathrm{Se}$ ) and $\mathrm{N}$, a various photochemical reaction pathways are possible, implying that the photochemical reaction mechanism of azoles derivatives is more complicated than that of aromatic hydrocarbons. Although photochemical behavior of some five-membered ring containing two hetero atoms has been investigated, ${ }^{7}$ the whole reaction pathways have not been completed yet. In the present study, we focus our attention on the photoreaction pathways of thiazole.

Several research groups have investigated the photochemistry of thiazole (1) and isothiazole $\left(\mathbf{1}^{\prime}\right)$ experimentally and theoretically. For example, Cateau et al. reported that the photoconversion from $\left(\mathbf{1}^{\prime}\right)$ to $(\mathbf{1})$ proceeds but not the reverse photoconversion from (1) to $\left(\mathbf{1}^{\prime}\right)$ in any solvents. ${ }^{8}$ By contrast, the final photodecomposition products of thiazole (1) in the gas phase were found to be cyano radical $\left({ }^{\circ} \mathrm{CN}\right)$ and thiocyanato radical ( ${ }^{\circ} \mathrm{NCS}$ ) using a flash photolysis technique, ${ }^{9}$ although the photodecomposition pathways have not been elucidated yet.

The low-temperature rare-gas matrix-isolation experiment is one of the most powerful techniques to study photoreaction pathways, because unstable or noble species are immediately frozen and trapped in low-temperature solid, which is chemically inert and no absorption in UV and visible-light regions, and stabilized in the environment without interactions between species and solvents. For example, the structure of a thiazole/ carbon suboxide $\left(\mathrm{C}_{3} \mathrm{O}_{2}\right)$ complex was investigated in argon matrices, ${ }^{\mathbf{1 0}}$ while the phosphorescence of thiazole in $\mathrm{Ne}, \mathrm{Ar}, \mathrm{Xe}$, $\mathrm{SF}_{6}$, and $\mathrm{CH}_{4}$ matrices at $4 \mathrm{~K}$ was measured. ${ }^{11}$ Most recently, the conformational changes of a thiazole derivative (thiazole-2carboxylic acid) isolated in $\mathrm{Ar}$ and $\mathrm{N}_{2}$ matrices have been reported by Halasa et al., using narrowband excitation with nearinfrared (IR) and UV light. ${ }^{12}$ However, the photoreaction pathways of matrix-isolated thiazole, the parent molecule with no substitution groups, have never been reported yet because of their complication, even though thiazole is one of the most fundamental heterocyclic compounds having two hetero atoms.

In the present study, the photochemical reactivity and stability of thiazole isolated in solid argon matrices are investigated by a joint use of IR spectroscopy and density-functionaltheory (DFT) calculations. Our purposes are to identify intermediates and final products in the photolysis of thiazole as many as possible, to examine absorbance changes of IR bands against irradiation time, to elucidate when and where and why ring-opening reaction, photoisomerization, and photodecomposition occur, and finally to propose the whole UV-induced photoreaction pathways of thiazole.

\section{Experimental}

The sample of thiazole (Tokyo Chemical Industry Co., Ltd., more than $98.0 \%$ purity) was degassed and purified by freezethaw cycles at $77 \mathrm{~K}$ and room temperature before using. Argon gas (Taiyo Nippon Sanso, 99.9999\% purity) was used without further purification. The sample vapor was premixed with argon gas in a vacuum line at room temperature. The experimental setup was reported in previous papers. ${ }^{\mathbf{1 3 , 1 4}}$ The mixed gas was condensed on a cold substrate (CsI) cooled to $20 \mathrm{~K}$ by a closedcycle helium refrigerator (Iwatani, Cryo Mini M310) through a stainless pipe of 1/8-inch o.d. over a period of $40 \mathrm{~min}$ so as to show good signal-to-noise spectra. After the deposition, the matrix sample was cooled down and kept at $10 \mathrm{~K}$ for recording IR spectral changes before and after UV irradiation.

IR spectra were measured with an FT-IR spectrometer (JEOL, JIR-WINSPEC50) equipped with an MCT detector cooled by liquid $\mathrm{N}_{2}$. All the spectra were measured at $0.5 \mathrm{~cm}^{-1}$ resolution and averaged over 64 scans. A super high-pressure mercury lamp (SHPML) (USHIO, BA-H500, $\lambda>200 \mathrm{~nm}$ ) was used to induce photoreactions. The IR region in the light source was filtered out using a water filter, the wavelength of the light source was controlled with/without optical glass filters.

DFT calculations were performed to obtain the optimized geometry, relative energies and IR spectral patterns of reactants, intermediates, and products using the GAUSSIAN03 program $^{\mathbf{1 5}}$ at the UB3LYP/aug-cc-pVTZ level among some calculation levels, where their electronic ground state is singlet. Other calculation conditions are default values in the program. Scaling factors of $0.96,0.97$ and 0.98 were applied to the regions over $2800 \mathrm{~cm}^{-1}$, between 2800 and $1900 \mathrm{~cm}^{-1}$, and below 1900 $\mathrm{cm}^{-1}$, respectively, in the present study so as to reproduce the observed wavenumbers for bands of the reactant, thiazole. TDDFT calculations were performed to obtain the vertical transition energy and oscillator strength at the same level.

\section{Results and discussion}

\subsection{IR spectra of thiazole in argon matrices}

IR spectra of thiazole in the vapor, liquid, and crystalline states were reported in the ref. 16 and those in the low-temperature inert-gas matrices were also reported in the ref. 12 The IR spectrum of thiazole (1) in an argon matrix at $10 \mathrm{~K}$, shown in Fig. 2a, is consistent with the reported IR spectra. To confirm the assignment of the observed bands, we decided to calculate the spectral pattern using a basis set of UB3LYP/aug-cc-pVTZ among some calculation levels, because this basis set is applicable to species containing sulfur atoms. Indeed, this basis set worked well for the assignments of photoisomerized products of thiophenol in argon matrices ${ }^{\mathbf{1 7}}$ and the fundamental bands of thiirane in the gas phase. ${ }^{18}$ The calculated spectral pattern for thiazole (1) is shown in Fig. 2 b, and the observed and calculated wavenumbers and the IR intensities are summarized in Table S1 of the ESI $\dagger$ with the assignments of vibrational modes. It is found that the observed IR spectrum in Fig. 2a is in good agreement with the calculated spectral pattern in Fig. $2 \mathrm{~b}$.

\subsection{Ring-opening reactions by cleavage of the $\mathrm{S} 1-\mathrm{C} 2$ bond with hydrogen-atom migration}

3.2.1. Identification of 2-isocyanoethenethiol $(\mathrm{C} \equiv \mathrm{N}-\mathrm{CH}=$ $\mathbf{C H}-\mathbf{S H})$. In order to investigate the photochemical stability and 


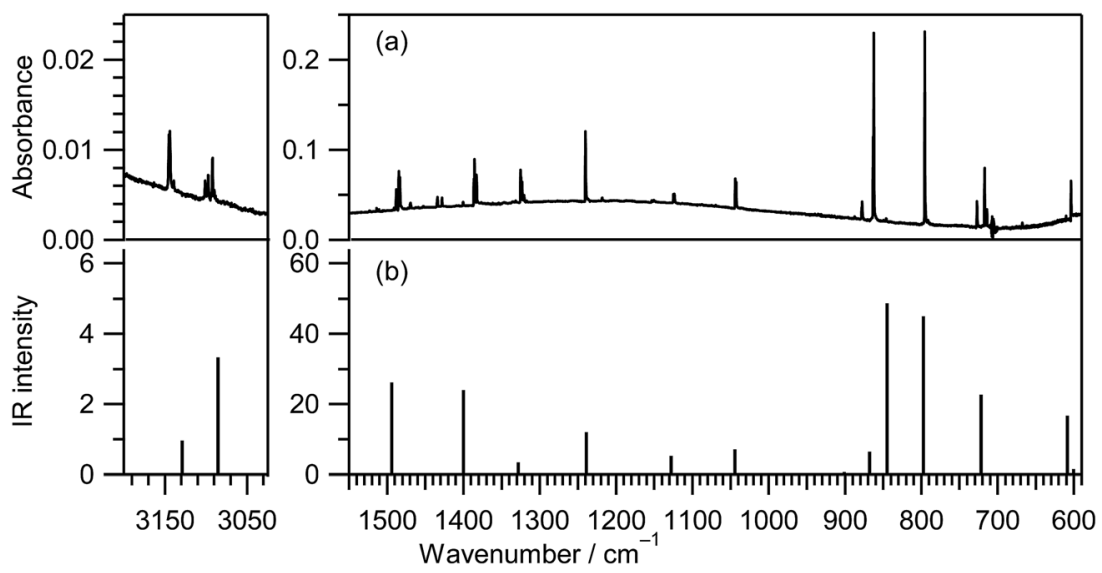

Fig. 2 (a) Observed IR spectrum of thiazole (1) isolated in a solid argon matrix at $10 \mathrm{~K}$. (b) Calculated spectral pattern of thiazole at the DFT/ UB3LYP/aug-cc-pVTZ level. Scaling factors of 0.96 and 0.98 are applied to the regions over $2800 \mathrm{~cm}^{-1}$ and below $1900 \mathrm{~cm}^{-1}$, respectively.

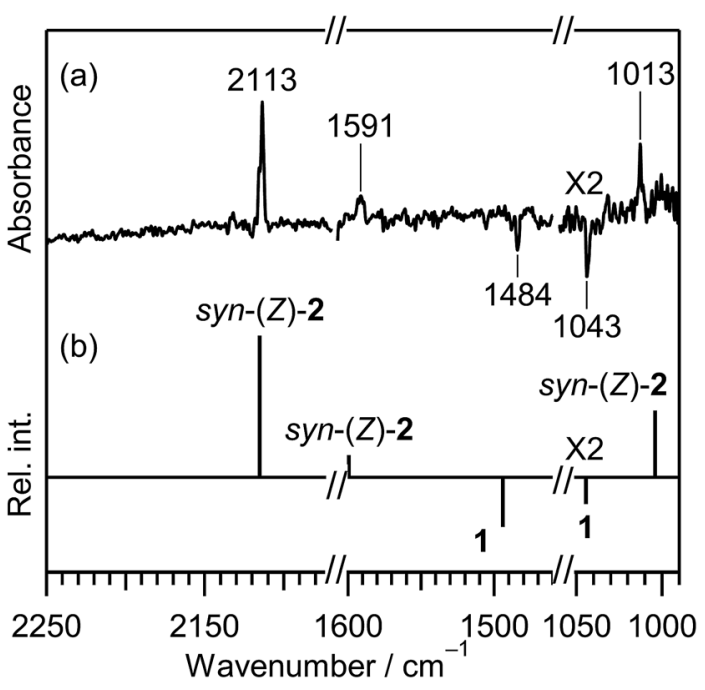

Fig. 3 (a) Difference IR spectrum of thiazole (1) isolated in a solid argon matrix between the spectra measured before and after UV irradiation for $3 \mathrm{~min}$. (b) Calculated spectral patterns of the reactant, thiazole (1), (negative) and the product, syn-(Z)-2-isocyaonoethenethiol (syn-(Z)-2), (positive) at the DFT/UB3LYP/aug-ccpVTZ level. Scaling factors of 0.97 and 0.98 are applied to the regions between 2800 to $1900 \mathrm{~cm}^{-1}$ and below $1900 \mathrm{~cm}^{-1}$, respectively.

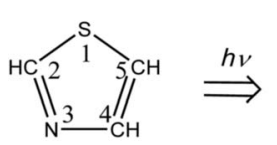

(1)

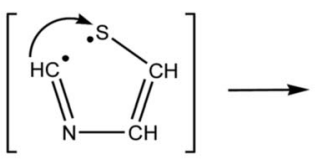

(syn-(Z)-2)

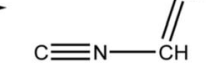

Scheme 1 Photoproduction pathway for syn-2-isocyanoethenethiol (syn-(Z)-2).

reactivity of thiazole (1), we exposed the matrix sample to UV radiation coming from a super high-pressure mercury lamp (SHPML) through various UV short-cutoff glass filters. When the light in the region with shorter wavelength than $270 \mathrm{~nm}$ was cut, no spectral changes were observed. This finding is consistent with the report on UV-visible absorption spectra of thiazole in six kinds of solvents, ${ }^{19}$ where thiazole in solution has absorption around 235 and $205 \mathrm{~nm}$ due to $\pi \rightarrow \pi^{*}$ transition. Therefore, we conclude that the photochemistry of thiazole (1) in the present study is promoted by radiation between 200 and $270 \mathrm{~nm}$ through the $\pi \rightarrow \pi^{*}$ transition.

A difference IR spectrum between the spectra measured before and after irradiation for only $3 \mathrm{~min}$ is shown in Fig. 3a, where the negative and positive bands indicate the reactant and the product, respectively. For example, the intensity of the 1484 and $1043 \mathrm{~cm}^{-1}$ bands of thiazole (1) decreased, and new bands appeared at 2113, 1591, and $1013 \mathrm{~cm}^{-1}$. The intense $2113 \mathrm{~cm}^{-1}$ band is characteristic of species containing an isocyano $(\mathrm{C} \equiv \mathrm{N}-)$ or cyano $(\mathrm{N} \equiv \mathrm{C}-)$ group. ${ }^{20}$ There are a few candidates of $\mathrm{C}_{3} \mathrm{H}_{3} \mathrm{NS}$ species including the triple bond, which have the same chemical formula as the parent molecule, thiazole (1). 2-Isocyanoethenethiol $(\mathrm{C} \equiv \mathrm{N}-\mathrm{CH}=\mathrm{CH}-\mathrm{SH})$ (2) is one of the candidates for the photoproducts of thiazole (1), which is produced by cleavage of the S1-C2 bond with the hydrogenatom migration from $\mathrm{C} 2$ to $\mathrm{S} 1$ (see Scheme 1). The existence of (2) was predicted previously by the DFT calculation (B3LYP/6$\left.31 \mathrm{G}^{*}\right),{ }^{21}$ but neither spectral parameters nor experimental evidences have yet been reported. Thus we have performed the DFT calculation for the geometrical optimization and the vibrational analysis of (2) to assign the bands newly appearing in Fig. 3.

Two conformations are possible around both the C-S single bond and the $\mathrm{C}=\mathrm{C}$ double bond of (2), resulting in the four planar conformers shown in Fig. 4. We call anti and syn for the former conformation and $(E)$ and $(Z)$ for the latter conformation. The optimized geometrical parameters and the relative energies are shown in Fig. 4. Syn-(Z)-2 is the most stable one among the four conformers, and anti-(Z)-2 is less stable than syn-(Z)-2 by $4.6 \mathrm{~kJ} \mathrm{~mol}^{-1}$, while both syn-(E)-2 and anti-(E)-2 are less stable than $\operatorname{syn}-(Z)-2$ by $\sim 8 \mathrm{~kJ} \mathrm{~mol}^{-1}$. The calculated wavenumbers and IR intensities of the bands for the four conformers are listed in Table S2 of the ESI. $\dagger$

The calculated spectral pattern of the most stable syn-(Z)-2 is shown in Fig. 3b to compare with the observed spectrum of the 


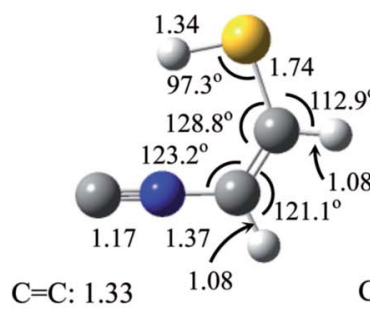

$\mathrm{C}=\mathrm{C}: 1.3$

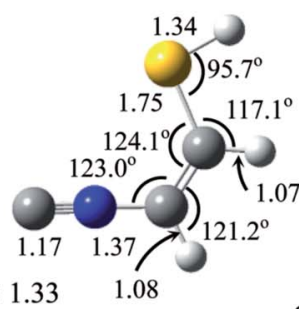

anti-(Z)-2

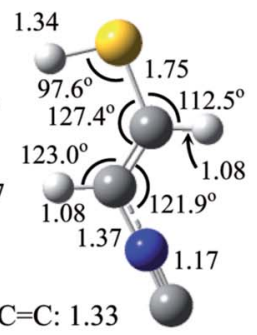

syn- $(E)-2$

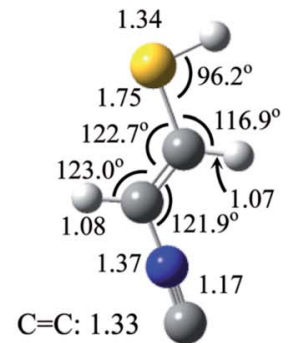

anti-(E)-2

$$
\begin{aligned}
& \Delta E=129.71 \mathrm{~kJ} \mathrm{~mol}^{-1} \Delta E=134.31 \mathrm{~kJ} \mathrm{~mol}^{-1} \Delta E=138.11 \mathrm{~kJ} \mathrm{~mol}^{-1} \Delta E=137.95 \mathrm{~kJ} \mathrm{~mol}^{-1} \\
& \begin{array}{llll}
\tau=0.0^{\circ} & \tau=0.0^{\circ} & \tau=180.0^{\circ} & \tau=179.8^{\circ}
\end{array}
\end{aligned}
$$

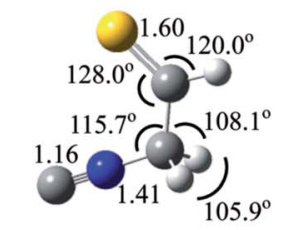

C-C: $1.50, \mathrm{C}-\mathrm{H}: 1.08$ syn-3

$$
\begin{gathered}
\Delta E=165.66 \mathrm{~kJ} \mathrm{~mol}^{-1} \\
\tau=0.0^{\circ}
\end{gathered}
$$

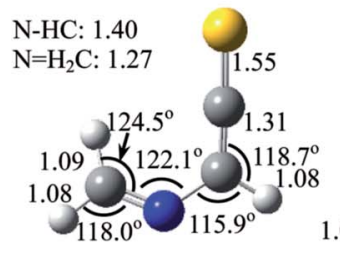

syn-5

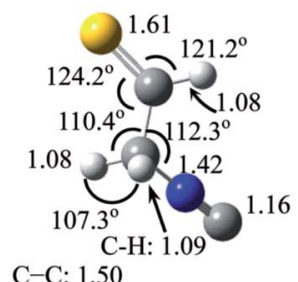

anti-3

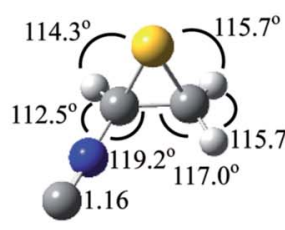

$\mathrm{S}-\left(\mathrm{H}_{2} \mathrm{C}\right): 1.82$, $\mathrm{S}-((\mathrm{CN}) \mathrm{HC}): 1.83$, C-H: $1.08, \mathrm{C}-\mathrm{C}: 1.48$ $7^{\circ}(\mathrm{HC})-\mathrm{N}: 1.39$ $<\mathrm{S}-\left(\mathrm{H}_{2} \mathrm{C}\right)-((\mathrm{CN}) \mathrm{HC}): 66.2^{\circ}$ $<\mathrm{S}-((\mathrm{CN}) \mathrm{HC})-\left(\mathrm{H}_{2} \mathrm{C}\right): 66.0^{\circ}$

4

$\Delta E=164.28 \mathrm{~kJ} \mathrm{~mol}^{-1}$

$$
\begin{gathered}
\Delta E=163.67 \mathrm{~kJ} \mathrm{~mol}^{-1} \\
\tau=152.0^{\circ}
\end{gathered}
$$

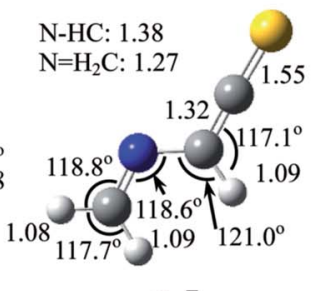

anti-5

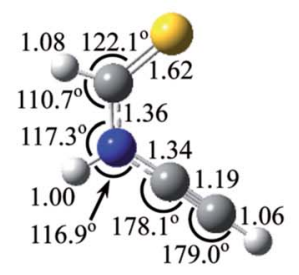

syn-6

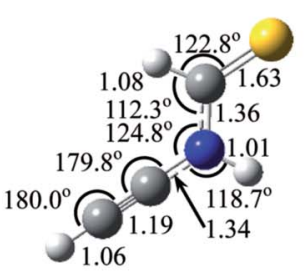

anti-6

$$
\begin{array}{cccc}
\Delta E=163.81 \mathrm{~kJ} \mathrm{~mol}^{-1} & \Delta E=153.77 \mathrm{~kJ} \mathrm{~mol}^{-1} & \Delta E=181.28 \mathrm{~kJ} \mathrm{~mol}^{-1} & \Delta E=172.08 \mathrm{~kJ} \mathrm{~mol}^{-1} \\
\tau=21.7^{\circ} & \tau=180^{\circ} & \tau=0^{\circ} & \tau=180^{\circ}
\end{array}
$$
$\Delta E=172.08 \mathrm{~kJ} \mathrm{~mol}^{-1}$ $\tau=180^{\circ}$

Fig. 4 Optimized structures and relative energies ( $\Delta E \mathrm{in} \mathrm{kJ} \mathrm{mol}{ }^{-1}$ based on thiazole (1)) of open-chain species calculated at the UB3LYP/aug-ccpVTZ level after ZPE correction. The numbers in figures represent bond lengths (in angstrom) and bonded angles (in degrees). The dihedral angle $\tau$ is defined as $\mathrm{C} \equiv \mathrm{N}-\mathrm{HC}=\mathrm{HC}-\mathrm{SH}(2), \mathrm{C} \equiv \mathrm{N}-\mathrm{H}_{2} \mathrm{C}-\mathrm{CH}=\mathrm{S}(3), \mathrm{CH}_{2}=\mathrm{N}-\mathrm{CH}=\mathrm{C}$ (5), and $\mathrm{C}-\mathrm{NH}-\mathrm{CH}=\mathrm{S}(6)$.

photoproduct. The most intense band at $2113 \mathrm{~cm}^{-1}$ is assignable to the $\mathrm{C} \equiv \mathrm{N}$ - stretching mode of $\operatorname{syn}-(\mathrm{Z})-2$, while the 1591 and $1013 \mathrm{~cm}^{-1}$ bands are assignable to the $\mathrm{C}=\mathrm{C}$ stretching and $\mathrm{S}-\mathrm{H}$ bending modes, respectively. Since the wavenumbers predicted by the DFT calculation are consistent with the corresponding observed values within $\sim 10 \mathrm{~cm}^{-1}$, as compared in Table 1, we conclude that $\operatorname{syn}-(Z)-2$ is the initial photoproduct of thiazole (1) in argon matrices.

3.2.2. Identification of 2-isocyanoethanethial $\left(\mathrm{C} \equiv \mathbf{N}-\mathrm{CH}_{2}-\right.$ $\mathbf{C H}=\mathbf{S}$ ). When the matrix sample was exposed to UV light for 10 min, new bands appeared at 2157, 2151, and $2132 \mathrm{~cm}^{-1}$ near the $\mathrm{C} \equiv \mathrm{N}-$ stretching band at $2113 \mathrm{~cm}^{-1}$ of $\operatorname{syn}-(Z)-2$, as shown in Fig. 5a. The intensities of the 2157 and $2151 \mathrm{~cm}^{-1}$ bands attractively increased when the irradiation time increased to $45 \mathrm{~min}$, as shown in Fig. 5b. These new bands could be due to the $\mathrm{C} \equiv \mathrm{N}-$ stretching mode of the photoproducts like the $2113 \mathrm{~cm}^{-1}$ band of syn-(Z)-2. We assume that the 2157 and $2151 \mathrm{~cm}^{-1}$ bands are assigned to 2-isocyanoethanethial $\left(\mathrm{C} \equiv \mathrm{N}-\mathrm{CH}_{2}-\mathrm{CH}=\mathrm{S}\right)(3)$, which has two conformations around the $\mathrm{C}-\mathrm{C}$ single bond, syn and anti. The optimized geometrical parameters and the relative energies of syn-3 and anti-3 are shown in Fig. 4, where the relative energy of anti-3 is nearly equal to that of $s y n-3$. All the calculated wavenumbers and IR intensities of the bands for syn-3 and anti-3 are summarized in Table S3 of the ESI. $\dagger$ It is found that the bands observed at 2157 and $2151 \mathrm{~cm}^{-1}$ in Fig. 5b correspond with the calculated IR bands due to the $\mathrm{C} \equiv \mathrm{N}$ - stretching modes of syn-3 and anti-3, 2163 and $2155 \mathrm{~cm}^{-1}$ in Fig. 5c, respectively.

IR bands of syn-3 and anti-3 in other spectral regions are very weak after UV irradiation for $45 \mathrm{~min}$. Thus we tried to find the bands of syn-3 and anti-3 in the difference spectrum between the 
Table 1 Observed and calculated wavenumbers, and relative intensities of 2-isocyanoethenethiol (2), 2-isocyanoethanethial (3), and 2-isocyanothiirane (4) in solid argon matrices

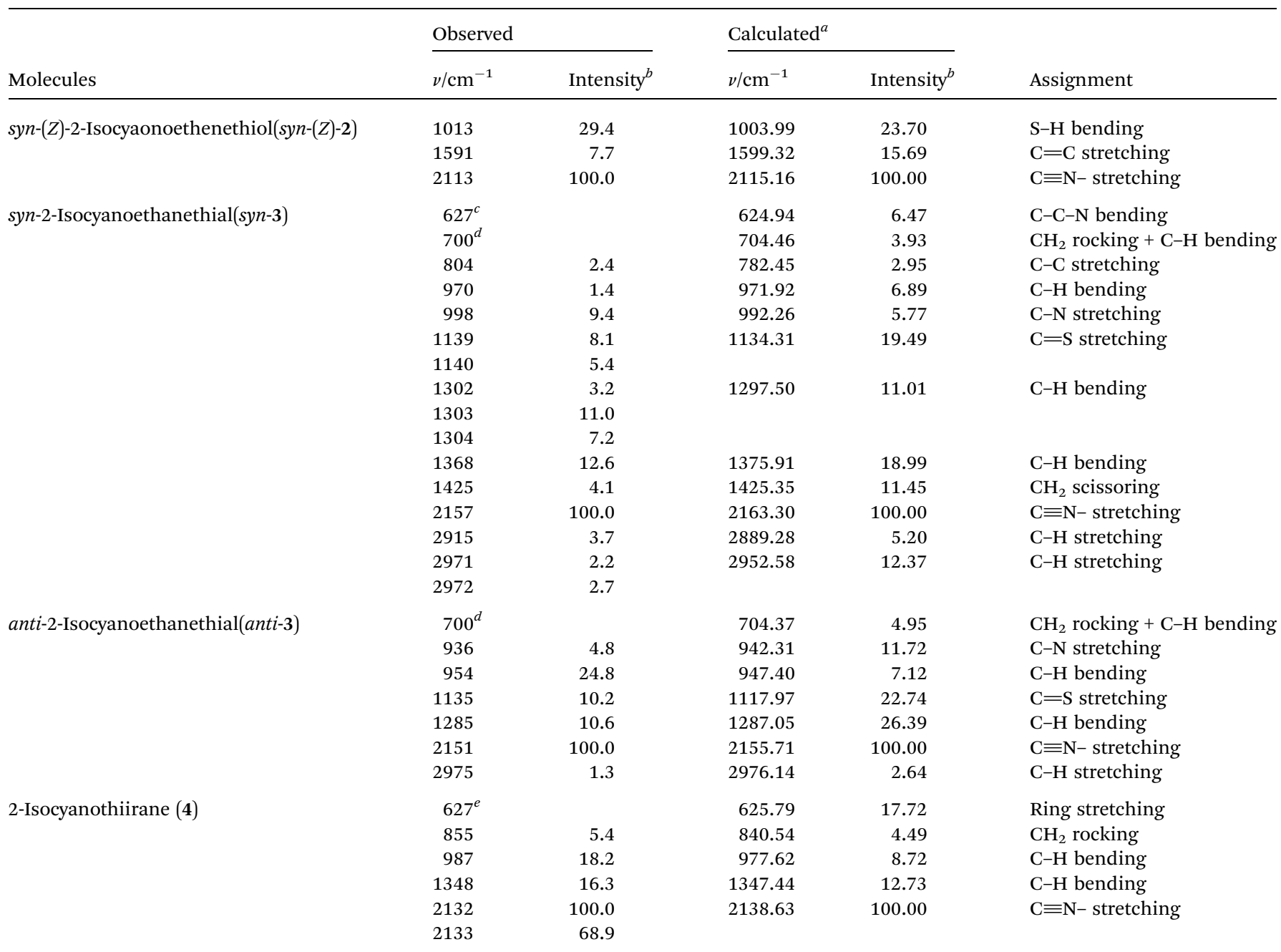

${ }^{a}$ Calculated at the DFT/UB3LYP/aug-cc-pVTZ level. Scaling factors of 0.96, 0.97, and 0.98 are applied to the regions over $2800 \mathrm{~cm}^{-1}$, between 2800 to $1900 \mathrm{~cm}^{-1}$, and below $1900 \mathrm{~cm}^{-1}$, respectively. ${ }^{b}$ Relative intensity is normalized to the most intense band. ${ }^{c}$ Overlapped with a band of (4).

${ }^{d}$ Overlapped with a band of ethenethione. ${ }^{e}$ Overlapped with a band of syn-3.

spectra measured after 180 min minus after 45 min UV irradiation (see Fig. 6). It is noted that the bands due to syn-(Z)-2 initially produced from thiazole (1) are negligible in this difference spectrum because their intensities are almost unchanged during this prolonged irradiation period, as described in Section 3.2.4. Several weak bands of syn-3 and anti-3 are detectable in Fig. 6 and marked with "syn-3" and "anti-3", respectively. The observed wavenumbers and relative intensities of the bands of syn-3 (12 vibrational modes) and anti-3 (7 vibrational modes) are consistent with the corresponding calculated values, as shown in Table 1 . Therefore, we conclude that both syn-3 and anti-3 are produced from thiazole (1) upon prolonged UV irradiation. The photoproduction pathways for syn-3 and anti-3 are discussed in Section 3.2.5 using the kinetic analysis of the IR absorbance changes against the irradiation time.

3.2.3. Identification of 2-isocyanothiirane. A weak band is detected at $2132 \mathrm{~cm}^{-1}$ in Fig. $5 \mathrm{a}$ and $\mathrm{b}$. This band appeared even in the photolysis of thiazole (1) for only 3 min (see Fig. 3), which is assignable to the $\mathrm{C} \equiv \mathrm{N}$ - stretching mode like the bands of $(Z)$ 2, syn-3 and anti-3 appearing at 2113, 2157, and $2151 \mathrm{~cm}^{-1}$, respectively. Since species including a three-membered ring are usually produced in the photolysis of five-membered heterocyclic compounds such as furan, ${ }^{22}$ thiophene, ${ }^{22}$ and isoxazole, ${ }^{23}$ we assume that this band is due to 2-isocyanothiirane (4), which is produced by cleavage of the $\mathrm{S} 1-\mathrm{C} 2$ bond, hydrogen-atom migration from $\mathrm{C} 2$ to $\mathrm{C} 5$, and then electron migration to make the S1-C4 bond (see Scheme 2). The optimized geometrical parameters and the relative energy of (4) are shown in Fig. 4; this species is less stable than that of syn-3 by only $0.61 \mathrm{~kJ}$ $\mathrm{mol}^{-1}$. All the calculated wavenumbers and IR intensities of (4) are listed in Table S3 of the ESI. $\dagger$ The wavenumbers and the relative intensities of the observed bands for (4) are compared with the corresponding calculated values in Table 1.

Initially, we considered that 2-isocyanothiirane (4) was produced from thiazole (1) via Dewar thiazole, because Dewar structures of five-membered ring molecules such as furan, ${ }^{22}$ 


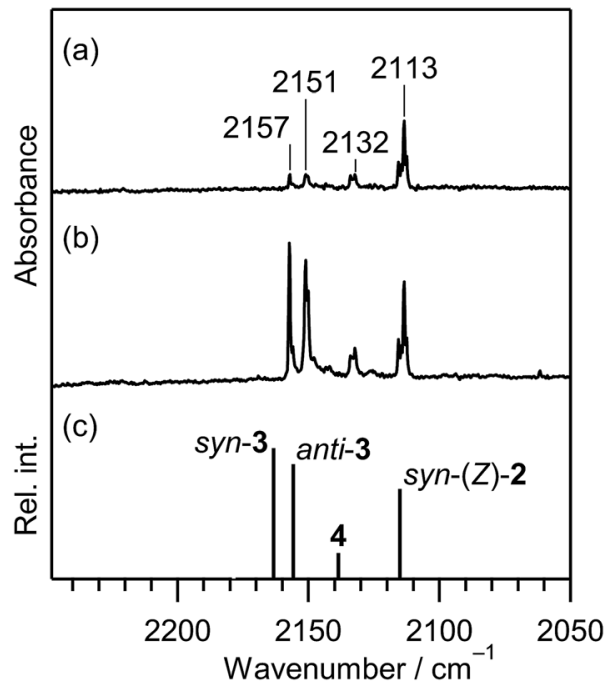

Fig. 5 Difference IR spectra of thiazole (1) isolated in a solid argon matrix at $10 \mathrm{~K}\left(2250-2050 \mathrm{~cm}^{-1}\right)$ between the spectra measured before and after UV-irradiation. Irradiation time is (a) $10 \mathrm{~min}$ and (b) $45 \mathrm{~min}$. (c) Calculated spectral patterns of 2-isocyanoethenethiol (syn(Z)-2), 2-isocyanoethanethial (syn-3 and anti-3), and 2-isocyanothiirane (4) at the DFT/UB3LYP/aug-cc-pVTZ level. A scaling factor of 0.97 is applied to this region.

thiophene, ${ }^{22}$ and cyclopentadiene ${ }^{24}$ were previously detected as intermediates in photolysis using the matrix-isolation technique. In addition, Dewar thiazole derivatives were theoretically

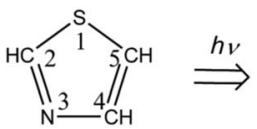

(1)

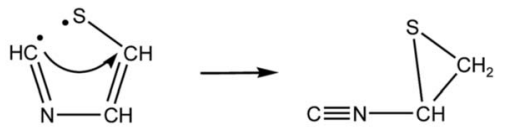

(4)
Scheme 2 Photoproduction pathway for 2-isocyanothiirane (4).

proposed as candidates of the photochemical intermediates for 2-phenylthiazole and 2-acetylthiazole. ${ }^{25}$ However, no IR bands of Dewar thiazole are found in our IR spectra around the wavenumbers predicted by our DFT calculations (see Table S4, ESI $\dagger$ ). For example, the most intense band due to the $\mathrm{C}-\mathrm{H}$ inplane bending mode is predicted at $1262.75 \mathrm{~cm}^{-1}$, but undetectable. The relative energy of Dewar thiazole is estimated to be higher than those of 2-isocyanothiirane (4) and thiazole (1) by 94.5 and $258.8 \mathrm{~kJ} \mathrm{~mol}^{-1}$, respectively, implying that Dewar thiazole is so unstable under our experimental condition to be detected. The photoproduction pathway shown in Scheme 2, where (4) is directly produced from thiazole (1), is supported by the kinetic analysis of the absorbance change against the irradiation time, as explained in the following section.

The photochemical behavior of thiazole derivatives such as methylthiazole and phenylthiazole in solvents were investigated theoretically ${ }^{25,26}$ and experimentally. ${ }^{27,28}$ It is reported that the photoconversion from the thiazole derivatives to the corresponding isothiazole derivatives occurs, where Dewar structures play a role of intermediates. If the photoconversion from

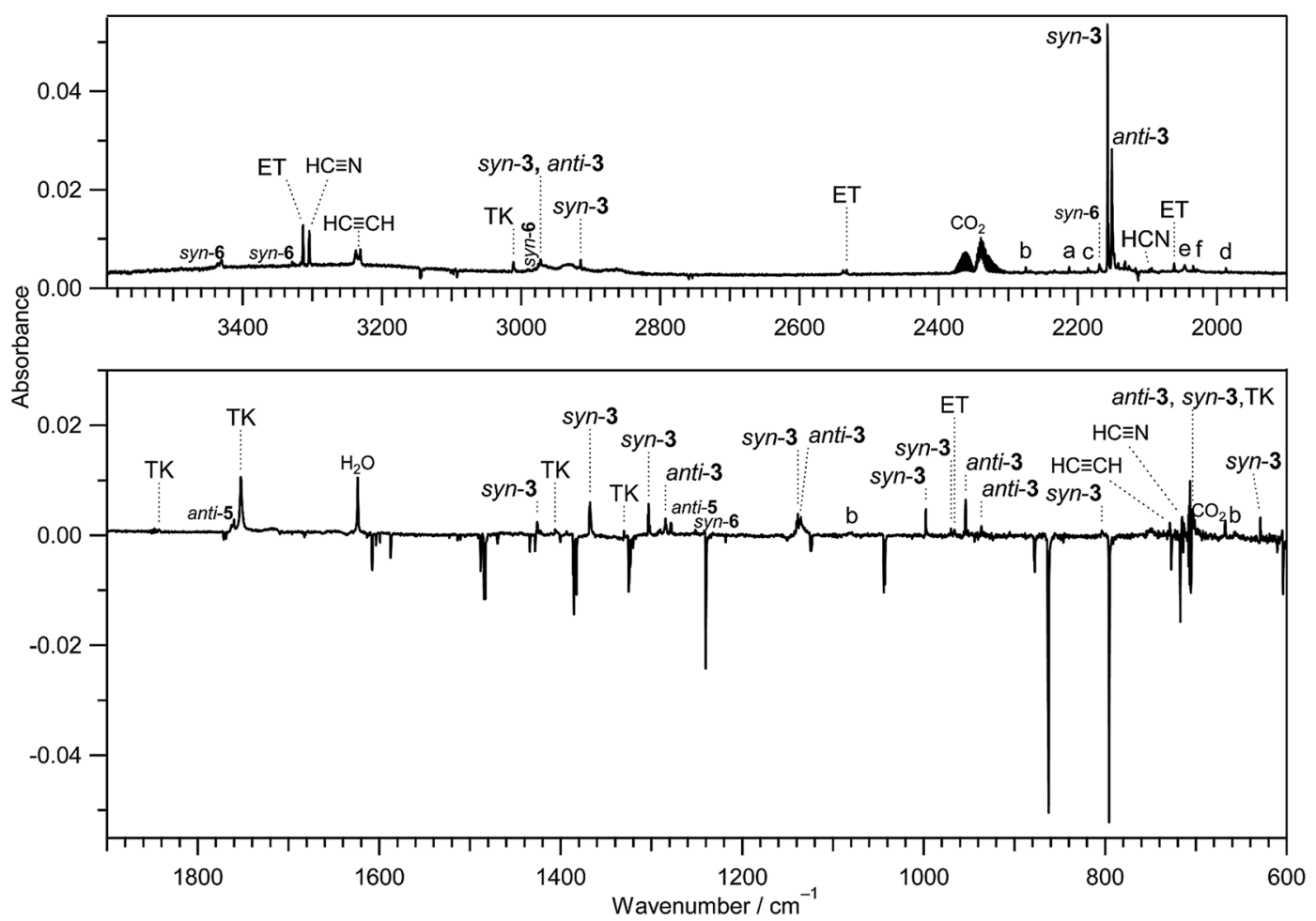

Fig. 6 Difference IR spectra of thiazole (1) isolated in a solid argon matrix at $10 \mathrm{~K}$ between the spectra measured after $180 \mathrm{~min}$ minus after $45 \mathrm{~min}$ UV irradiation. TK and ET denote thioketene $\left(\mathrm{CH}_{2}=\mathrm{C}=\mathrm{S}\right)$ and ethynethiol $(\mathrm{HC} \equiv \mathrm{C}-\mathrm{SH})$, respectively. Bands marked with "a", "b", "c", "d", "e", and " $\mathrm{f}$ " are tentatively assigned to 2 -cyanoethenethiol $(\mathrm{N} \equiv \mathrm{C}-\mathrm{CH}=\mathrm{CH}-\mathrm{SH}), 2$-cyanothiirane, $\mathrm{N} \equiv \mathrm{C}-\mathrm{SH}, \mathrm{HN}=\mathrm{C}=\mathrm{S}, \mathrm{CN}$ radical, and $\mathrm{HC} \equiv \mathrm{NS}$, respectively. 


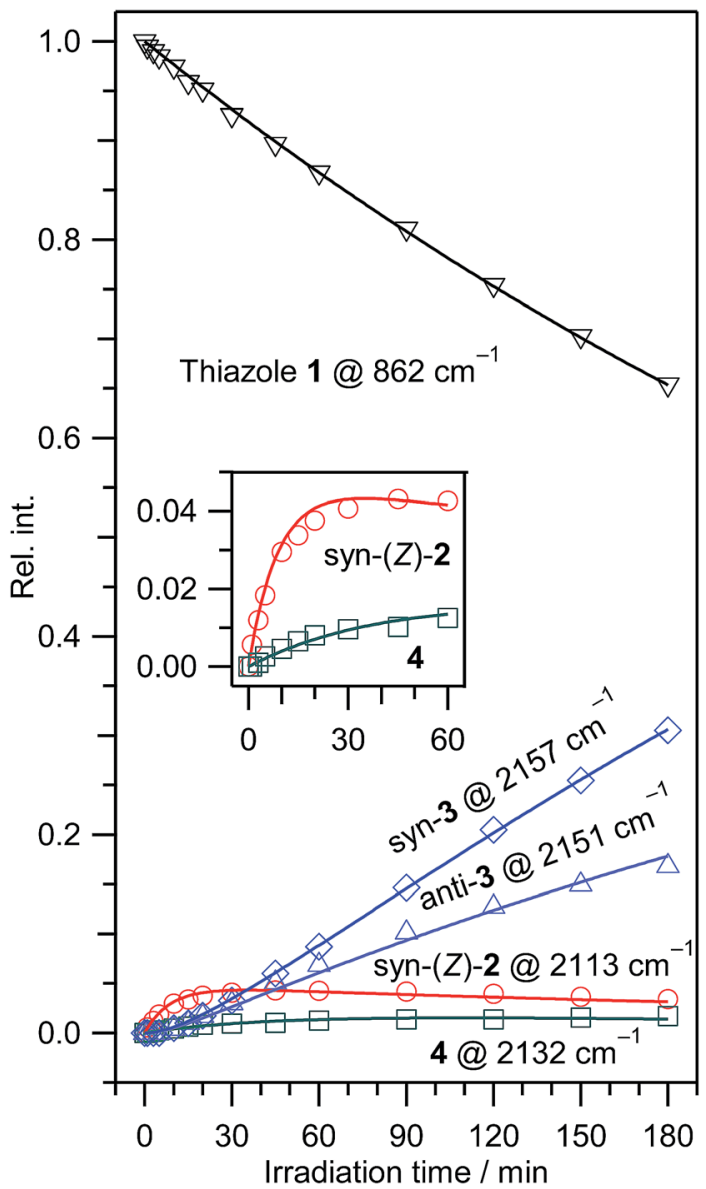

Fig. 7 Absorbance changes against irradiation time for thiazole (1), 2isocyanoethenethiol (syn-(Z)-2), 2-isocyanoethanethial (syn-3 and anti-3), and 2-isocyanothiirane (4). The absorbance is normalized using the absorbance of the band at $862 \mathrm{~cm}^{-1}$ for thiazole (1) before UV irradiation. The solid lines represent calculated values obtained by least-squares fitting (see the text). The panel in the graph shows the enlarged absorbance changes of syn-(Z)-2 and (4) at the early irradiation stage $(0-60 \mathrm{~min})$

thiazole (1) to isothiazole $\left(\mathbf{1}^{\prime}\right)$ is accelerated in low-temperature argon matrices, we could detect the IR bands of isothiazole $\left(\mathbf{1}^{\prime}\right)$. However, no corresponding bands near the 726, 819, 1239, and $1391 \mathrm{~cm}^{-1}$ bands reported in the gas phase ${ }^{29}$ were detected in the difference spectrum shown in Fig. 6. This fact also supports our conclusion that Dewar thiazole is not produced from thiazole (1) under our experimental condition.

3.2.4. Absorbance changes of IR bands for 1, 2, 3, and 4. To the best of our knowledge, the isocyano compounds, (2), (3), and (4), have been experimentally identified for the first time in the present study. To support our assignments and understand the photoreaction pathways of thiazole (1), we examined the absorbance changes of the $862 \mathrm{~cm}^{-1}$ (thiazole (1)), $2113 \mathrm{~cm}^{-1}$ (syn-(Z)-2), $2157 \mathrm{~cm}^{-1}$ (syn-3), $2151 \mathrm{~cm}^{-1}$ (anti-3), and $2132 \mathrm{~cm}^{-1}$ (4) bands against the irradiation time in Fig. 7. The absorbance of the band for thiazole (1) decreases, while that of the bands for syn-(Z)-2 and (4) increases immediately after starting UV irradiation (see the inserted panel of Fig. 7). Since syn-(Z)-2 and (4)

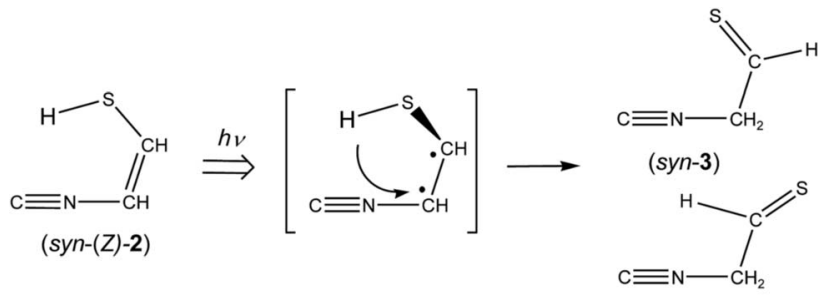

(anti-3)

Scheme 3 Photoisomerization from 2-isocyanoethenethiol (2) to 2isocyanoethanethial (3).

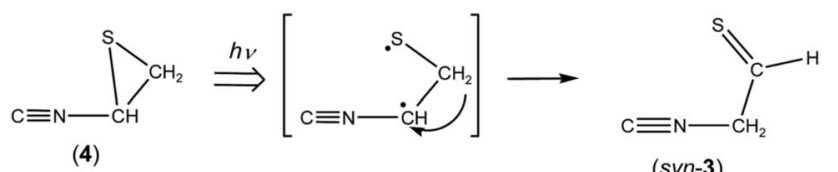

Scheme 4 Photoisomerization from 2-isocyanothiirane (4) to syn-2isocyanoethanethial (syn-3).

reveal no induction periods at the early irradiation stage, these species could be directly photoproduced from thiazole (1).

The absorbance of syn-(Z)-2 slightly decreased upon prolonged irradiation over $45 \mathrm{~min}$, as shown in Fig. 7, indicating that syn-(Z)-2 changes to other species by the secondary photoinduced reactions. On the other hand, the absorbance of syn-3 and anti-3 increases more slowly than that of $s y n-(Z)-2$ and clearly reveals induction periods at the early irradiation stage. Thus we assume that syn-3 and anti-3 are photoproduced from syn-(Z)-2 by hydrogen-atom migration from $\mathrm{S} 1$ to $\mathrm{C} 4$ with generation of the $\mathrm{C}=\mathrm{S}$ double bond (see Scheme 3). If the $\mathrm{SH}$ group in the photoexcited state of $\operatorname{syn}-(Z)-2$ is perpendicular to the other part $(\mathrm{C} \equiv \mathrm{N}-\mathrm{CH})$, it is reasonable to assume that both $s y n-3$ and anti-3 are produced from syn-(Z)-2.

In contrast to the fact that the absorbance of thiazole (1) continues to decrease upon prolonged irradiation over $45 \mathrm{~min}$, the absorbance of (4) is nearly constant as shown in Fig. 7, indicating that a partial amount of (4) changes to other species by the secondary photo-induced reactions like $s y n-(Z)-2$. It is noted that the absorbance of the band for syn-3 increases more strongly over $45 \mathrm{~min}$ irradiation than that for anti-3. Thus we assume that syn-3 is also photoproduced from (4) by hydrogenatom migration from $\mathrm{C} 5$ to $\mathrm{C} 4$ with generation of the $\mathrm{C}=\mathrm{S}$ double bond (see Scheme 4). To explain this selective photoproduction of syn-3 but not anti-3, we assume that the isocyano group in (4) moves to the opposite side against the hydrogen atom migrating from the methylene group. In this case, the attraction between the sulfur atom and the nitrogen atom in the photoexcited state of (4) may play an important role for the selectivity, which is an interesting problem especially for theoretical chemists. We support the selective photoreaction pathway by the kinetic analysis of the absorbance changes described in the following section.

3.2.5. Kinetic analysis. In order to confirm Schemes 1-4 proposed above, we have performed kinetic analysis of the 
absorbance changes of the IR bands for (1), syn-(Z)-2, syn-3, anti-3, and (4) against the irradiation time shown in Fig. 7, where the rate constants for the photoreaction pathways are defined as follows:

$$
\begin{gathered}
(\mathbf{1}) \rightarrow(\operatorname{syn}-(Z)-\mathbf{2})+(\mathbf{4}), \text { rate constant: } k_{1} \\
(\operatorname{syn}-(Z)-\mathbf{2}) \rightarrow \text { syn-3 }+ \text { anti-3, rate constant: } k_{2} \\
(\mathbf{4}) \rightarrow \text { syn-3, rate constant: } k_{3}
\end{gathered}
$$

Five rate equations are derived from the above reaction pathways of (1)-(3) as follows,

$$
\begin{gathered}
\mathrm{d}[(\mathbf{1})] / \mathrm{d} t=-k_{1}[(\mathbf{1})], \\
\mathrm{d}[\operatorname{syn}-(Z)-2] / \mathrm{d} t=k_{1}[(\mathbf{1})]-k_{2}[\operatorname{syn}-(Z)-\mathbf{2}], \\
\mathrm{d}[(\mathbf{4})] / \mathrm{d} t=k_{1}[(\mathbf{1})]-k_{3}[(\mathbf{4})], \\
\mathrm{d}[\operatorname{syn}-\mathbf{3}] / \mathrm{d} t=k_{2}[\operatorname{syn}-(Z)-\mathbf{2}]+k_{3}[(\mathbf{4})], \\
\mathrm{d}[a n t i-3] / \mathrm{d} t=k_{2}[(\operatorname{syn}-(Z)-\mathbf{2})],
\end{gathered}
$$

where [ ] represents the number of each species. These differential equations are solved easily in terms of absorbance $A$ and absorption coefficient $\varepsilon$, resulting in the following equations,

\begin{tabular}{|c|c|c|c|}
\hline & $\begin{array}{l}\text { Vertical transition } \\
\text { energy/nm }\end{array}$ & $\begin{array}{l}\text { Oscillator } \\
\text { strength }\end{array}$ & $\begin{array}{l}\text { Obsd. } \\
\text { wavelength }{ }^{b} / \mathrm{nm}\end{array}$ \\
\hline \multirow[t]{2}{*}{ Thiazole } & 221.54 & 0.0715 & $\sim 235$ \\
\hline & 199.38 & 0.0362 & $\sim 205$ \\
\hline (S1-C2 cleavage) & 293.15 & 0.1669 & \\
\hline${ }^{\circ} \mathrm{CH}=\mathrm{N}-\mathrm{CH}=\mathrm{CH}-\mathrm{S}^{\circ}$ & & & \\
\hline (C5-S1 cleavage) & 251.48 & 0.1600 & \\
\hline${ }^{\circ} \mathrm{CH}=\mathrm{CH}-\mathrm{N}=\mathrm{CH}-\mathrm{S}^{\circ}$ & & & \\
\hline $\begin{array}{l}\text { (N3-C4 cleavage) } \\
\cdot \mathrm{N}=\mathrm{CH}-\mathrm{S}-\mathrm{CH}=\mathrm{CH}^{\cdot}\end{array}$ & 195.14 & 0.1314 & \\
\hline
\end{tabular}

$$
\begin{gathered}
A_{(\mathbf{1})}=A_{0} \exp \left(-k_{1} t\right), \\
A_{(s y n-(Z)-2)}=\left(\varepsilon_{(s y n-(Z)-2)} / \varepsilon_{(\mathbf{1})}\right) A_{0}\left\{\alpha \exp \left(-k_{1} t\right)-\alpha \exp \left(-k_{2} t\right)\right\}, \\
A_{(\mathbf{4})}=\left(\varepsilon_{(\mathbf{4})} / \varepsilon_{(\mathbf{1})}\right) A_{0}\left\{\beta \exp \left(-k_{1} t\right)-\beta \exp \left(-k_{3} t\right)\right\},
\end{gathered}
$$

Table 2 Vertical transition energy and oscillator strength of biradicals produced by cleavage of the $\mathrm{S} 1-\mathrm{C} 2, \mathrm{C} 5-\mathrm{S} 1$, or N3-C4 bond in thiazole (1) ${ }^{a}$

$$
\begin{gathered}
A_{(\text {syn-3) }}=\left(\varepsilon_{(\operatorname{syn}-\mathbf{3})} / \varepsilon_{(\mathbf{1})}\right) A_{0}\left\{2-\left(k_{2} / k_{1}\right) \alpha \exp \left(-k_{1} t\right)-\left(k_{3} / k_{1}\right) \beta \exp \left(-k_{1} t\right)\right. \\
\left.+\alpha \exp \left(-k_{2} t\right)+\beta \exp \left(-k_{3} t\right)\right\}, \\
A_{(\text {anti-3) }}=\left(\varepsilon_{(\text {anti-3) }} / \varepsilon_{(\mathbf{1})}\right) A_{0}\left[1-\left(k_{2} / k_{1}\right) \alpha \exp \left(-k_{1} t\right)+\alpha \exp \left(-k_{2} t\right)\right],
\end{gathered}
$$

where $\alpha$ and $\beta$ denote $k_{1} /\left(k_{2}-k_{1}\right)$ and $k_{1} /\left(k_{3}-k_{1}\right)$, respectively. The absorbance of thiazole (1) at $t=0, A_{0}$, is fixed to 1 because the absorbance shown in Fig. 7 is normalized using the $A_{0}$ value.

We have performed the least-squares fitting for the absorbance changes using the eqn (9)-(13) to determine three rate constants of $k_{1}, k_{2}$, and $k_{3}$ and four ratios of absorption coefficients such as $\varepsilon_{(\mathbf{4})} / \varepsilon_{(\mathbf{1})}$. The obtained rate constants are 0.00236 $\pm 0.00001,0.112 \pm 0.010$, and $0.0228 \pm 0.0040 \mathrm{~min}^{-1}$ for $k_{1}, k_{2}$, and $k_{3}$, respectively, and the obtained ratios of absorption coefficients are $2.23 \pm 0.18,0.190 \pm 0.028,0.506 \pm 0.013$, and $0.536 \pm 0.007$ for $\varepsilon_{(\text {syn-(Z)-2) }} / \varepsilon_{(\mathbf{1})}, \varepsilon_{(\mathbf{4})} / \varepsilon_{(\mathbf{1})}, \varepsilon_{(\text {syn-3) }} / \varepsilon_{(\mathbf{1})}$, and $\varepsilon_{(\text {anti-3) }} / \varepsilon_{(\mathbf{1})}$, respectively, where the uncertainty represents one standard deviation. The rate constant $k_{2}$ is five times larger than $k_{3}$, meaning that the reactivity of $s y n-(Z)-2$ is higher than that of (4). The ratio of absorption coefficients for syn-3 and anti-3 is calculated to be $0.506 / 0.536=0.944$, which is almost consistent with the corresponding value obtained by the DFT calculation, 174.5/183.6 $=0.950$ (see Table S3, ESI $\dagger$ ). The calculated absorbance for each species is drawn by solid lines in Fig. 7, which reproduces the observed values satisfactorily, strongly supporting our proposed reaction pathways shown in Schemes $1-4$.

\subsection{Photodecompositions by two cleavages of the S1-C2 and N3-C4 bonds with hydrogen-atom migration}

The ring-opening species initially produced by cleavage of the $\mathrm{S} 1-\mathrm{C} 2$ bond is ${ }^{\circ} \mathrm{CH}=\mathrm{N}-\mathrm{CH}=\mathrm{CH}-\mathrm{S}^{\cdot}$ biradical. In order to confirm that this biradical absorbs UV light, we have performed the time-dependent density-functional-theory (TD-DFT) calculations for vertical transition energy and oscillator strength. The obtained value is $293.15 \mathrm{~nm}$ with the oscillator strength of 0.167 as listed in Table 2, the wavelength being longer than that of thiazole (1), $221.54 \mathrm{~nm}$, and the oscillator strength being two times larger than that of thiazole (1), 0.071. Therefore, we assume that ${ }^{\circ} \mathrm{CH}=\mathrm{N}-\mathrm{CH}=\mathrm{CH}-\mathrm{S} \cdot$ immediately absorbs the second photon to cleave the N3-C4 bond, resulting in the coproduction of $\mathrm{HC} \equiv \mathrm{N}$ and ${ }^{\circ} \mathrm{CH}=\mathrm{CH}-\mathrm{S}{ }^{\cdot}$ biradical. The hydrogen atom on the center carbon atom of ${ }^{\circ} \mathrm{CH}=\mathrm{CH}-\mathrm{S}^{*}$ immediately migrates to the end carbon atom to form ethenethione (thioketene, $\mathrm{CH}_{2}=\mathrm{C}=\mathrm{S}$ ) or to the sulfur atom to form ethynethiol ( $\mathrm{HC} \equiv \mathrm{C}-\mathrm{SH})$, as shown in Scheme 5.

Several papers reported the bands of $\mathrm{HC} \equiv \mathrm{N}$ in the gas phase $^{30}$ and in the low-temperature matrices ${ }^{23,31-34}$ to be $\sim 3303$ and $\sim 720 \mathrm{~cm}^{-1}$ for the $\mathrm{C}-\mathrm{H}$ stretching and bending modes,

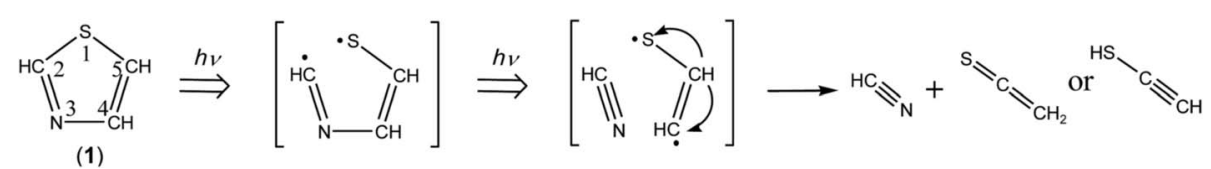

Scheme 5 Photodecomposition pathway to $\mathrm{HC} \equiv \mathrm{N}$ and $\mathrm{CH}_{2}=\mathrm{C}=\mathrm{S}$ or $\mathrm{HC} \equiv \mathrm{C}-\mathrm{SH}$. 
Table 3 Observed and reported wavenumbers and relative intensities of photofragments, $\mathrm{CH}_{2}=\mathrm{C}=\mathrm{S}, \mathrm{HC} \equiv \mathrm{C}-\mathrm{SH}$, and $\mathrm{HC} \equiv \mathrm{N}$, in solid argon matrices

\begin{tabular}{lccll}
\hline Obsd. $\nu / \mathrm{cm}^{-1}$ & Intensity $^{a}$ & $\operatorname{Ar}^{2}$ matrix $^{b}$ & & Assignment \\
\hline Ethenethione & $\left(\mathbf{C H}_{2}=\mathrm{C}=\mathrm{S}\right)$ & & & \\
$700^{c}$ & & 692 & $\mathrm{~S}$ & $\mathrm{CH}_{2}$ wagging \\
1330 & 11.5 & 1322 & $\mathrm{~m}$ & \\
1410 & 2.1 & 1410 & $\mathrm{~W}$ & \\
1752 & 100.0 & 1755 & $\mathrm{vs}$ & $\mathrm{C}=\mathrm{C}=\mathrm{S}$ stretching \\
1843 & 3.4 & 1840 & $\mathrm{~m}$ & \\
3011 & 20.9 & 3010 & $\mathrm{~m}$ & $\mathrm{C}-\mathrm{H}$ stretching
\end{tabular}

Ethynethiol (HC $\equiv \mathrm{C}-\mathrm{SH})$

$\begin{array}{lrrll}d & & 558 & \text { w } & \text { C-H bending } \\ 966 & 10.3 & 959 & \text { w } & \text { S-H bending } \\ d & & 1112 & \text { m } & \\ 2062 & 19.5 & 2065 & \text { w } & \text { C } \equiv \text { C stretching } \\ 2532 & 10.9 & 2575 & \text { vw } & \text { S-H stretching } \\ 3313 & 100.0 & 3315 & \text { vs } & \text { C-H stretching }\end{array}$

${ }^{a}$ Relative intensity is normalized to the most intense band. ${ }^{b}$ Ref. 40 . Symbols of vs, s, m, w, and vw denote very strong, strong, medium, weak, and very weak, respectively. ${ }^{c}$ Overlapped with bands of syn-3 and anti-3. ${ }^{d}$ Undetectable. ${ }^{e}$ Ref. $32 .{ }^{f}$ Ref. 35.

Hydrogen cyanide $(\mathrm{HC} \equiv \mathrm{N})$

\begin{tabular}{lcccl}
\hline Obsd. $\nu / \mathrm{cm}^{-1}$ & Intensity $^{a}$ & Ar matrix $^{e}$ & Armatrix $^{f}$ & Assignment \\
\hline 715 & 45.6 & 720.2 & 721 & C-H bending \\
2094,2097 & 10.0 & 2093.4 & 2098 & N $\equiv$ C- stretching \\
3304 & 100.0 & 3303.3 & 3306 & C-H stretching
\end{tabular}

respectively. The $3304 \mathrm{~cm}^{-1}$ and $715 \mathrm{~cm}^{-1}$ bands observed in Fig. 6 are consistent with the values of $\mathrm{HC} \equiv \mathrm{N}$ (3306 and 721 $\mathrm{cm}^{-1}$ ) produced by the photolysis of $s$-tetrazine and $s$-triazine in

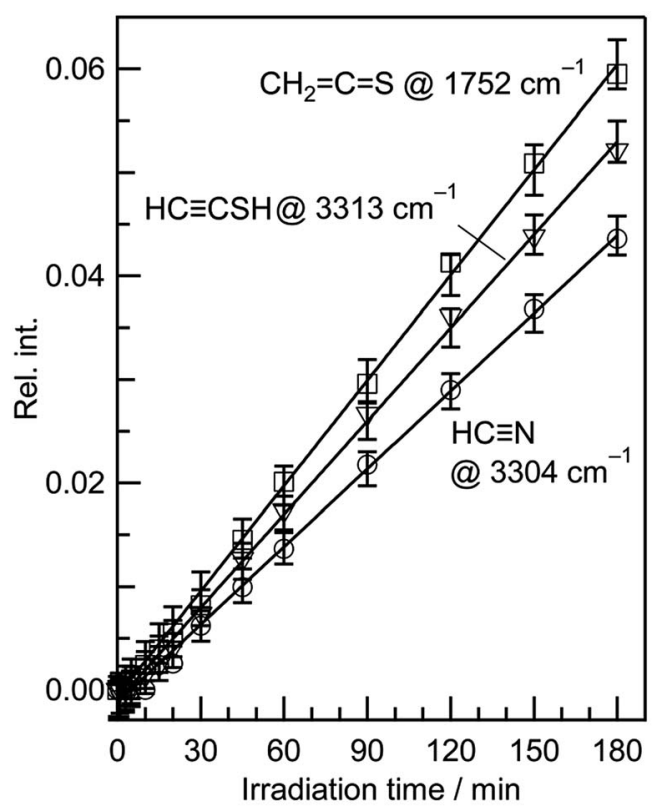

Fig. 8 Absorbance changes against irradiation time for $\mathrm{HC} \equiv \mathrm{N}, \mathrm{CH}_{2}=$ $\mathrm{C}=\mathrm{S}$, and $\mathrm{HC} \equiv \mathrm{CSH}$. The absorbance is normalized using the absorbance of the band at $862 \mathrm{~cm}^{-1}$ for thiazole (1) before UV irradiation in Fig. 7. argon matrices. ${ }^{35}$ Thus we conclude that $\mathrm{HC} \equiv \mathrm{N}$ is produced by the cleavage of the $\mathrm{N} 3-\mathrm{C} 4$ following the cleavage of the $\mathrm{S} 1-\mathrm{C} 2$ bond according to Scheme 5 .

There is an intense band at $1752 \mathrm{~cm}^{-1}$ marked with "TK" in Fig. 6. This band is characteristic of the $\mathrm{C}=\mathrm{C}=\mathrm{S}$ stretching mode of thioketene derivatives. For example, the bands of trimethylenethioketene and cyclopentylidenthioketene were observed at 1793 and $1790 \mathrm{~cm}^{-1}$ in argon matrices at $10 \mathrm{~K},{ }^{36,37}$ respectively, while the corresponding bands of methylthioketene $\left(\mathrm{CH}_{3}-\mathrm{CH}=\mathrm{C}=\mathrm{S}\right)$ and vinylthioketene $\left(\mathrm{CH}_{2}=\mathrm{CH}-\right.$ $\mathrm{CH}=\mathrm{C}=\mathrm{S}$ ) were observed at 1777 and $1740 \mathrm{~cm}^{-1}$ in argon matrices at $12 \mathrm{~K}^{38,39}$ Since the wavenumber of the $1752 \mathrm{~cm}^{-1}$ band observed in Fig. 6 is close to that of the $\mathrm{C}=\mathrm{C}=\mathrm{S}$ stretching mode of $\mathrm{CH}_{2}=\mathrm{C}=\mathrm{S}$ in argon matrices, ${ }^{\mathbf{4 0}} 1755$ $\mathrm{cm}^{-1}$, we conclude that $\mathrm{CH}_{2}=\mathrm{C}=\mathrm{S}$ is produced in the photolysis of thiazole (1). The $\mathrm{C}-\mathrm{H}$ stretching band of $\mathrm{CH}_{2}=$ $\mathrm{C}=\mathrm{S}$, which is reported to be $3010 \mathrm{~cm}^{-1}$ in argon matrices, is also detected at $3011 \mathrm{~cm}^{-1}$. Six bands marked with "TK" in Fig. 6 are assignable to $\mathrm{CH}_{2}=\mathrm{C}=\mathrm{S}$. The observed and reported wavenumbers and the relative intensities are summarized in Table 3.

$\mathrm{HC} \equiv \mathrm{C}-\mathrm{SH}$ was previously identified as a photoproduct of 1,2,3-thiadiazole, ${ }^{\mathbf{4 0}}$ where the characteristic IR bands due to the $\mathrm{C}-\mathrm{H}, \mathrm{S}-\mathrm{H}$, and $\mathrm{C} \equiv \mathrm{C}$ stretching modes were observed at 3315, 2575 , and $2065 \mathrm{~cm}^{-1}$, respectively. The $3313 \mathrm{~cm}^{-1}$ band marked with "ET" in Fig. 6 is consistent with the reported $3315 \mathrm{~cm}^{-1}$ band. In addition, the bands due to the $\mathrm{C} \equiv \mathrm{C}$ stretching and S-H bending modes are detected at 2062 and $966 \mathrm{~cm}^{-1}$, respectively (see Table 3), while the $\mathrm{S}-\mathrm{H}$ stretching band is

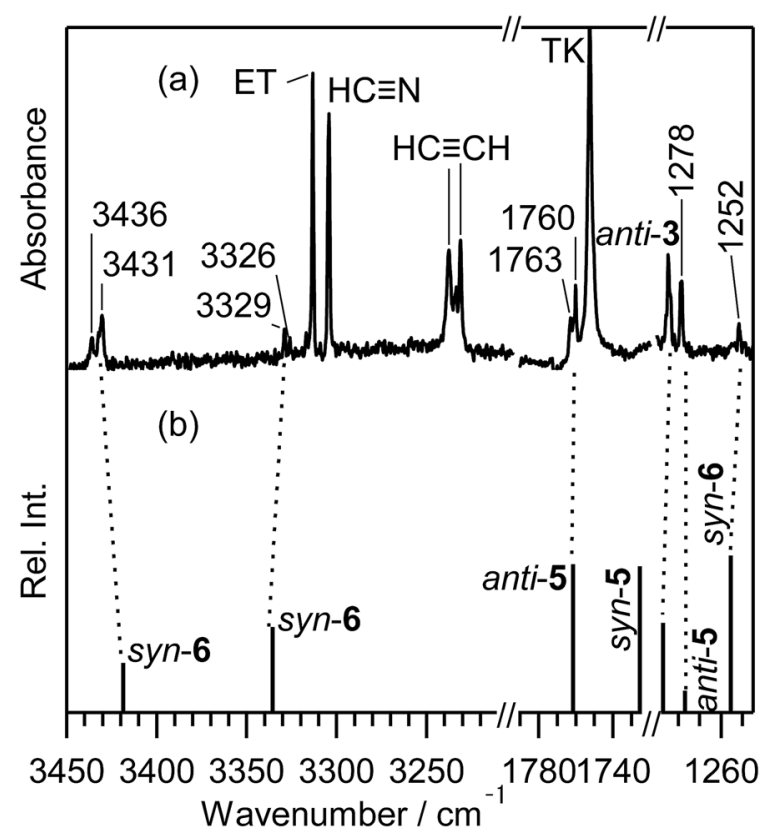

Fig. 9 Enlarged difference spectra (3450-3200, 1790-1720, and 1290-1250 $\mathrm{cm}^{-1}$ ) of Fig. 6. (a) Observed difference spectra. (b) Calculated spectral patterns of anti-2-isocyanoethanethial (anti-3), (methyleneamino)-ethenethione (anti-5 and syn-5), and syn-N-ethynylthioformamide (syn-6) at the DFT/UB3LYP/aug-cc-pVTZ level. Scaling factors of 0.96 and 0.98 are applied to regions over $2800 \mathrm{~cm}^{-1}$ and below $1900 \mathrm{~cm}^{-1}$, respectively. 
detected at $2532 \mathrm{~cm}^{-1}$. Thus we conclude that $\mathrm{HC} \equiv \mathrm{C}-\mathrm{SH}$ is coproduced from thiazole (1) with $\mathrm{HC} \equiv \mathrm{N}$ by the cleavage of the $\mathrm{N} 3-\mathrm{C} 4$ bond following the cleavage of the $\mathrm{S} 1-\mathrm{C} 2$ bond like $\mathrm{CH}_{2}=\mathrm{C}=\mathrm{S}$. The detection of the IR bands for $\mathrm{HC} \equiv \mathrm{N}, \mathrm{CH}_{2}=$ $\mathrm{C}=\mathrm{S}$ and $\mathrm{HC} \equiv \mathrm{C}-\mathrm{SH}$ supports the photodecomposition pathway shown in Scheme 5.

It is known that $\mathrm{HC} \equiv \mathrm{C}-\mathrm{SH}$ is converted to $\mathrm{CH}_{2}=\mathrm{C}=\mathrm{S}$ by hydrogen-atom migration upon UV irradiation. ${ }^{40}$ However, the absorbance of the bands for both $\mathrm{CH}_{2}=\mathrm{C}=\mathrm{S}$ and $\mathrm{HC} \equiv \mathrm{C}-\mathrm{SH}$ increase linearly with no induction periods at the early irradiation state, as shown in Fig. 8. Thus we assume that $\mathrm{CH}_{2}=\mathrm{C}=\mathrm{S}$ and $\mathrm{HC} \equiv \mathrm{C}-\mathrm{SH}$ are independently produced from thiazole (1) by cleavage of the N3-C4 bond following the cleavage of the $\mathrm{S} 1-\mathrm{C} 2$ bond with the hydrogen-atom migration according to Scheme 5. One may claim that $\mathrm{HC} \equiv \mathrm{N}, \mathrm{CH}_{2}=\mathrm{C}=\mathrm{S}$, and $\mathrm{HC} \equiv \mathrm{C}-\mathrm{SH}$ are produced by cleavage of the S1-C2 bond following the cleavage of the N3-C4 bond. However, the vertical transition energy of ${ }^{\circ} \mathrm{N}=\mathrm{CH}-\mathrm{S}-$ $\mathrm{CH}=\mathrm{CH}^{\circ}$, which is produced by cleavage of the N3-C4 bond, is calculated to be $195.14 \mathrm{~nm}$ with the oscillator strength of 0.1314 , as listed in Table 2 . Since the intensity of the light source of our SHPML with shorter wavelength than $200 \mathrm{~nm}$ is extremely weak, the secondary photolysis of ${ }^{\circ} \mathrm{N}=$ $\mathrm{CH}-\mathrm{S}-\mathrm{CH}=\mathrm{CH}^{*}$ is difficult in contrast to the hydrogen-atom migration in the primary photolysis described in Section 3.4.3.

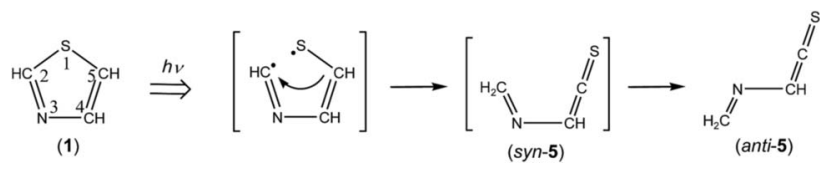

Scheme 6 Photoproduction pathway for anti-(methyleneamino)ethenethione (anti-5).
3.4 Minor ring-opening reactions by cleavage of the $\mathrm{S} 1-\mathrm{C} 2$, C5-S1, or N3-C4 bond with hydrogen-atom migration

3.4.1. Identification of (methyleneamino)-ethenethione $\left(\mathbf{C H}_{\mathbf{2}}=\mathbf{N}-\mathbf{C H}=\mathbf{C}=\mathbf{S}\right)$. The spectral region of the $\mathrm{C}=\mathrm{C}=\mathrm{S}$ stretching mode of Fig. $6\left(1790-1720 \mathrm{~cm}^{-1}\right)$ is enlarged in Fig. 9. One weak doublet band is detected at the higher-wavenumber side of the $\mathrm{CH}_{2}=\mathrm{C}=\mathrm{S}$ band marked with "TK". By comparison of the observed wavenumbers with the predicted values of many candidates obtained by the DFT calculation, we assume that the 1760 and $1763 \mathrm{~cm}^{-1}$ doublet band is due to the $\mathrm{C}=\mathrm{C}=\mathrm{S}$ stretching mode of (methyleneamino)-ethenethione $\left(\mathrm{CH}_{2}=\mathrm{N}-\mathrm{CH}=\mathrm{C}=\mathrm{S}\right)$ (5). This species is photoproduced by cleavage of the S1-C2 bond in thiazole (1) with the hydrogenatom migration from C5 to C2 (see Scheme 6), instead of the hydrogen-atom migration from $\mathrm{C} 2$ to $\mathrm{S} 1$ to form $s y n-(Z)-2$ (see Scheme 1) or from C2 to C5 to form (4) (see Scheme 2).

This species (5) has two conformations around the N3-C4 single bond (syn-5 and anti-5). The optimized geometrical parameters and the relative energies are shown in Fig. 4. All the calculated wavenumbers and IR intensities of both anti-5 and syn-5 are listed in Table S5 of the ESI. $\dagger$ The conformation of (5) photoproduced initially could be syn-5 but not anti-5, because the molecular shape of syn-5 is more similar to that of the reactant, thiazole (1), than that of anti-5. However, the DFT calculation reveals that syn-5 is less stable than anti-5 by $10.04 \mathrm{~kJ}$ $\mathrm{mol}^{-1}$, probably because of the strong repulsion between $\pi$ electrons on the $\mathrm{C}=\mathrm{N}$ and $\mathrm{C}=\mathrm{C}=\mathrm{S}$ double bonds like 1,3butadiene. ${ }^{41,42}$ Note that the optimized structure of $s y n-5$ is nonplanar and the dihedral angle around $\mathrm{CH}_{2}=\mathrm{N}-\mathrm{CH}=\mathrm{C}$ is calculated to be $21.7^{\circ}$ (see Fig. 4). The weak doublet band detected at 1760 and $1763 \mathrm{~cm}^{-1}$ in Fig. 9 is found to be consistent with the calculated value of the $\mathrm{C}=\mathrm{C}=\mathrm{S}$ stretching mode of anti-5, $1761.49 \mathrm{~cm}^{-1}$, but not with that of syn-5, 1725.47 $\mathrm{cm}^{-1}$. In addition, the $\mathrm{C}-\mathrm{H}$ bending mode of anti-5 is detected

Table 4 Observed and calculated wavenumbers, and relative intensities of (methyleneamino)-ethenethione (5) and $N$-ethynylthioformamide (6) in solid argon matrices

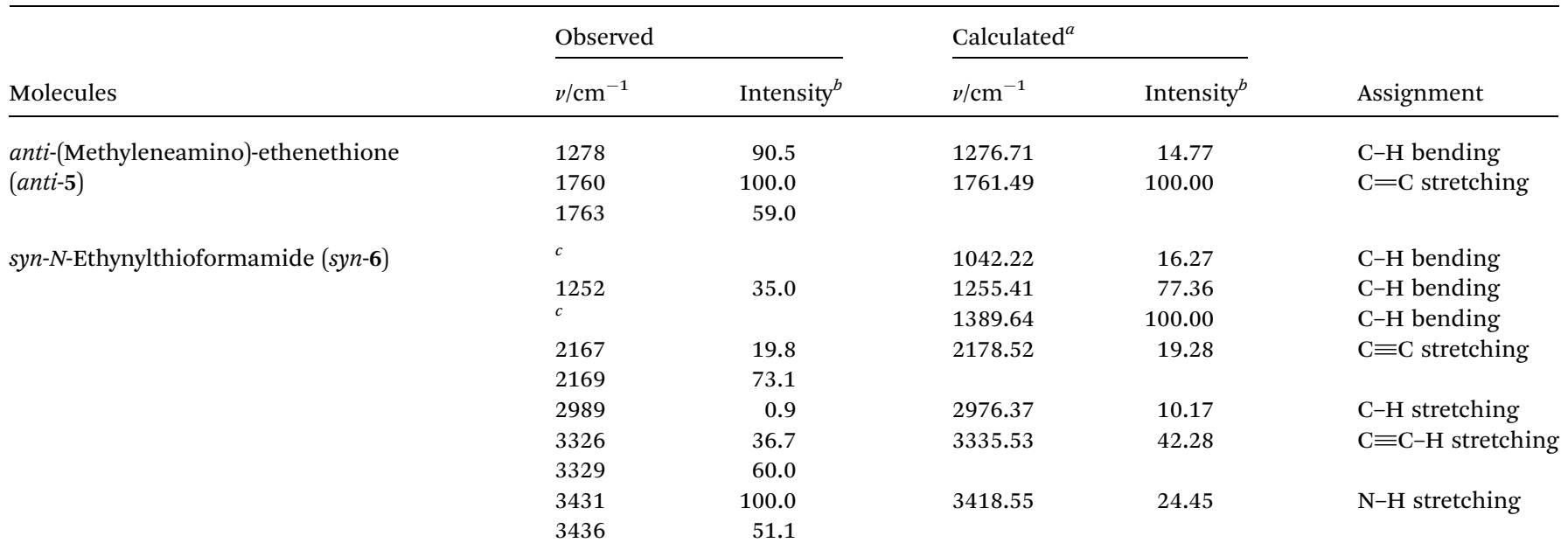

${ }^{a}$ Calculated at the DFT/UB3LYP/aug-cc-pVTZ level. Scaling factors of 0.96, 0.97 , and 0.98 are applied to the regions over $2800 \mathrm{~cm}^{-1}$, between 2800 and $1900 \mathrm{~cm}^{-1}$, and below $1900 \mathrm{~cm}^{-1}$, respectively. ${ }^{b}$ Relative intensity is normalized to the most intense band. ${ }^{c}$ Overlapped with bands of the reactant. 
<smiles></smiles>

(1)
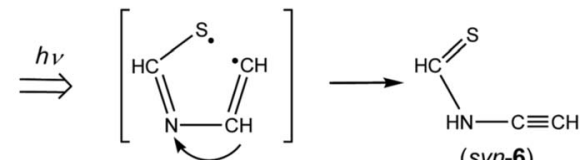

(syn-6)
Scheme 7 Photoproduction pathway for syn-N-ethynylformamide (syn-6).

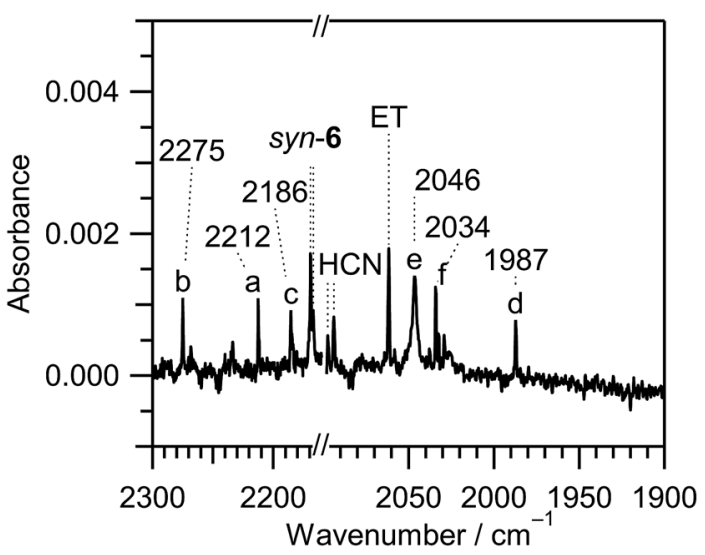

Fig. 10 Enlarged difference spectra (2300-2160 and 2100-1900 $\mathrm{cm}^{-1}$ ) of Fig. 6 . The spectral region between 2160 and $2100 \mathrm{~cm}^{-1}$ is omitted because the intensity of the IR bands of syn- 3 and anti- 3 is too strong. Bands marked with "a", "b", "c", "d", "e", and "f" are tentatively assigned to 2-cyanoethenethiol ( $\mathrm{N} \equiv \mathrm{C}-\mathrm{CH}=\mathrm{CH}-\mathrm{SH}$ ), 2-cyanothiirane, $\mathrm{N} \equiv \mathrm{C}-\mathrm{SH}, \mathrm{HN}=\mathrm{C}=\mathrm{S}, \cdot \mathrm{CN}$ radical, and $\mathrm{HC} \equiv \mathrm{NS}$, respectively.

at $1278 \mathrm{~cm}^{-1}$ in Fig. 9. Thus we conclude that anti-5 is produced from thiazole (1) via syn-5 initially photoproduced in an argonmatrix cage according to Scheme 6 . The observed and calculated wavenumbers and the relative intensities of anti-5 are compared in Table 4.

3.4.2. Identification of $\mathbf{N}$-ethynylthioformamide ( $\mathrm{HC} \equiv \mathrm{C}$ $\mathbf{N H}-\mathbf{C H}=\mathbf{S}$ ). Four bands are detected at 3436, 3431, 3329, and $3326 \mathrm{~cm}^{-1}$ in the $\mathrm{N}-\mathrm{H}$ or $\mathrm{C}-\mathrm{H}$ stretching region of Fig. 9 besides the bands of $\mathrm{HC} \equiv \mathrm{C}-\mathrm{SH}$ (marked with "ET"), $\mathrm{HC} \equiv \mathrm{N}$, and $\mathrm{HC} \equiv \mathrm{CH}$; the assignment of $\mathrm{HC} \equiv \mathrm{CH}$ is described in Section 3.6. As compared with the results obtained by the DFT calculations, we assign the 3436 and $3431 \mathrm{~cm}^{-1}$ doublet band and the 3329 and $3326 \mathrm{~cm}^{-1}$ doublet band to the $\mathrm{N}-\mathrm{H}$ and the $\mathrm{C}-\mathrm{H}$ stretching modes of $\mathrm{N}$-ethynylthioformamide ( $\mathrm{HC} \equiv \mathrm{C}-\mathrm{NH}-$ $\mathrm{CH}=\mathrm{S}$ ) (6), respectively. The optimized structures and the geometrical parameters of two conformers, syn-6 and anti-6, are shown in Fig. 4. All the calculated wavenumbers and IR intensities are listed in Table S5 of the ESI. $\dagger$ It is possible to produce syn-6 from thiazole (1) by cleavage of the C5-S1 bond with hydrogen-atom migration from $\mathrm{C} 4$ to $\mathrm{N} 3$ to generate the $\mathrm{C}=\mathrm{S}$ double bond (see Scheme 7). The band due to the $\mathrm{C} \equiv \mathrm{C}$ stretching mode of syn-6 is also detected as a weak doublet band at 2169 and $2167 \mathrm{~cm}^{-1}$ in Fig. 10, while the band due to the $\mathrm{C}-\mathrm{H}$ bending mode is detected at $1252 \mathrm{~cm}^{-1}$ in Fig. 9. The observed and calculated wavenumbers and the relative intensities of syn$\mathbf{6}$ are compared in Table 4.

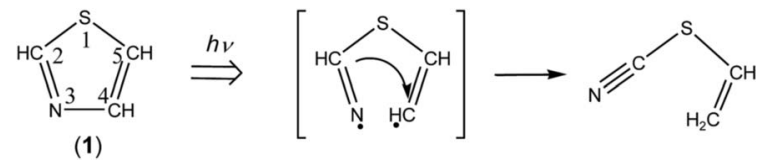

Scheme 8 Photoproduction pathway for thiocyanatoethene.

We could not identify the other conformer, anti-6, although the relative energy of anti-6 estimated to be lower than that of syn-6 by $9.20 \mathrm{~kJ} \mathrm{~mol}^{-1}$. For example, neither the most intense band around $1250 \mathrm{~cm}^{-1}$ nor the second intense band around $1500 \mathrm{~cm}^{-1}$ is detectable in Fig. 6. We have performed the onestep optimization between anti-6 and syn-6, resulting in the barrier height of $\sim 80 \mathrm{~kJ} \mathrm{~mol}^{-1}$ at the dihedral angles of 105 and $285^{\circ}$ (see Fig. S1, ESI $\dagger$ ). Thus we assume that the barrier height is so high that the conversion from syn-6 initially produced from thiazole (1) to the more stable conformer, anti-6, is unable to occur in an argon-matrix cage.

It is noted that the absorbance of the bands for anti-5 and syn-6 is much weaker than that of anti-3, syn-3, $\mathrm{HC} \equiv \mathrm{N}, \mathrm{CH}_{2}=$ $\mathrm{C}=\mathrm{S}$, and $\mathrm{HC} \equiv \mathrm{C}-\mathrm{SH}$, as shown in Fig. 6 . Thus we conclude that the photoreaction pathways to form anti-5 by the cleavage of the S1-C2 bond shown in Scheme 6 and to form syn-6 by the cleavage of the C5-S1 bond shown in Scheme 7 are minor ringopening reactions.

3.4.3. Identification of thiocyanatoethene ( $\equiv \mathrm{C}-\mathrm{S}-\mathrm{CH}=$ $\mathbf{C H}_{2}$ ). When the N3-C4 bond cleaves upon UV irradiation, ${ }^{\circ} \mathrm{N}=$ $\mathrm{CH}-\mathrm{S}-\mathrm{CH}=\mathrm{CH}^{*}$ biradical is produced, from which thiocyanatoethene $\left(\mathrm{N} \equiv \mathrm{C}-\mathrm{S}-\mathrm{CH}=\mathrm{CH}_{2}\right)$ could be produced by hydrogen-atom migration from $\mathrm{C} 2$ to $\mathrm{C} 4$ (see Scheme 8). The $\mathrm{N} \equiv \mathrm{C}$ - stretching band of $\mathrm{N} \equiv \mathrm{C}-\mathrm{S}-\mathrm{CH}=\mathrm{CH}_{2}$ is reported to be $2177 \mathrm{~cm}^{-1}$ in the vapor phase or $2172 \mathrm{~cm}^{-1}$ in argon matrices at $14 \mathrm{~K},{ }^{43}$ which is close to the two weak bands of syn-6 appearing at 2167 and $2169 \mathrm{~cm}^{-1}$ in Fig. 10. One of the two bands may be assigned to $\mathrm{N} \equiv \mathrm{C}-\mathrm{S}-\mathrm{CH}=\mathrm{CH}_{2}$. However, no IR bands of $\mathrm{N} \equiv \mathrm{C}-$ $\mathrm{S}-\mathrm{CH}=\mathrm{CH}_{2}$ in other spectral regions are detected in Fig. 6 unlike anti-5 and syn-6. We do not have much confidence for the identification of $\mathrm{N} \equiv \mathrm{C}-\mathrm{S}-\mathrm{CH}=\mathrm{CH}_{2}$.

\subsection{Minor photoconversions of isocyano group to cyano group in $s y n-(Z)-2$ and (4)}

2-Cyanoethenethiol $(\mathrm{N} \equiv \mathrm{C}-\mathrm{CH}=\mathrm{CH}-\mathrm{SH})$, which is known as a species of astrochemical interest, ${ }^{44}$ is one of the candidates of $\mathrm{C}_{3} \mathrm{H}_{3} \mathrm{NS}$ species including a cyano group. Only the direction of the $\mathrm{N} \equiv \mathrm{C}$ group of 2-cyanoethenethiol $(\mathrm{N} \equiv \mathrm{C}-\mathrm{CH}=\mathrm{CH}-\mathrm{SH})$ is different from that of 2-isocyanoethenethiol $(\mathrm{C} \equiv \mathrm{N}-\mathrm{CH}=\mathrm{CH}-$ $\mathrm{SH}$ ) identified in Section 3.2.1. The IR spectra of $\mathrm{N} \equiv \mathrm{C}-\mathrm{CH}=$ $\mathrm{CH}-\mathrm{SH}$ were measured previously, and the $\mathrm{N} \equiv \mathrm{C}$ - stretching band is reported to be $2223.7 \mathrm{~cm}^{-1}$ in the gas phase ${ }^{44}$ or 2214 $\mathrm{cm}^{-1}$ in film ${ }^{45}$ at $77 \mathrm{~K}$. We tentatively assign the weak band at $2212 \mathrm{~cm}^{-1}$ marked with "a" in Fig. 10 to $\mathrm{N} \equiv \mathrm{C}-\mathrm{CH}=\mathrm{CH}-\mathrm{SH}$. This species may be produced by detachment and recombination of the $\mathrm{CN}$ group in $\mathrm{C} \equiv \mathrm{N}-\mathrm{CH}=\mathrm{CH}-\mathrm{SH}$.

2-Cyanothiirane could be caused by detachment and recombination of the $\mathrm{CN}$ group in 2-isocianothiirane (4) like the 


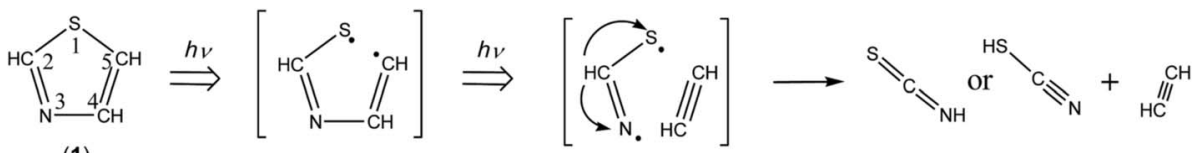

(1)

Scheme 9 Photodecomposition pathway to $\mathrm{HC} \equiv \mathrm{CH}$ and $\mathrm{N} \equiv \mathrm{C}-\mathrm{SH}$ or $\mathrm{HN}=\mathrm{C}=\mathrm{S}$.

photoconversion from $\mathrm{C} \equiv \mathrm{N}-\mathrm{CH}=\mathrm{CH}-\mathrm{SH}$ to $\mathrm{N} \equiv \mathrm{C}-\mathrm{CH}=\mathrm{CH}-$ $\mathrm{SH}$. The calculated wavenumbers and IR intensities of 2-cyanothiirane are shown in Table S4 of the ESI. $\dagger$ The $\mathrm{N} \equiv \mathrm{C}-$ stretching band is predicted at $2276 \mathrm{~cm}^{-1}$, and the corresponding band is detected at $2275 \mathrm{~cm}^{-1}$, marked with " $\mathrm{b}$ " in Fig. 10. The most intense band due to the $\mathrm{C}-\mathrm{S}$ symmetric stretching mode, $629 \mathrm{~cm}^{-1}$, and the thirdly intense band due to the $\mathrm{CH}_{2}$ waging mode, $1065 \mathrm{~cm}^{-1}$, are also detected at 658 and $1079 \mathrm{~cm}^{-1}$ in Fig. 6, respectively. Thus we conclude that a small amount of syn-(Z)-2 and (4), which are initially produced from thiazole (1), convert to the corresponding cyano compounds upon prolonged UV irradiation.

\subsection{Minor photodecompositions by two cleavages of the C5- S1 and N3-C4 bonds with hydrogen-atom migration}

As described in Section 3.4.2, the ring-opening species initially produced by cleavage of the $\mathrm{C} 5-\mathrm{S} 1$ bond is ${ }^{\circ} \mathrm{CH}=\mathrm{CH}-\mathrm{N}=\mathrm{CH}-\mathrm{S}{ }^{*}$ biradical. Since the vertical transition energy of ${ }^{\circ} \mathrm{CH}=\mathrm{CH}-\mathrm{N}=$ $\mathrm{CH}-\mathrm{S}^{*}$ is calculated to be $251.48 \mathrm{~nm}$ with the oscillator strength of 0.1600 , as listed in Table 2, the N3-C4 bond can be cleaved in the secondary photolysis to co-produce $\mathrm{CH} \equiv \mathrm{CH}$ and ${ }^{*} \mathrm{~N}=\mathrm{CH}-$ $\mathrm{S}^{\bullet}$ biradical. The hydrogen atom of ${ }^{*} \mathrm{~N}=\mathrm{CH}-\mathrm{S}^{\cdot}$ immediately migrates to the nitrogen atom to form $\mathrm{HN}=\mathrm{C}=\mathrm{S}$ or to the sulfur atom to form $\mathrm{N} \equiv \mathrm{C}-\mathrm{SH}$ as shown in Scheme 9.

A lot of papers have reported the wavenumbers of the vibrational modes for $\mathrm{HC} \equiv \mathrm{CH}$ in low-temperature matrices ${ }^{46-50}$ and in the gas phase. ${ }^{51}$ We detected the 3238, 3234 and 3231 $\mathrm{cm}^{-1}$ triplet band in Fig. 6, which is in good agreement with the reported value for $\mathrm{HC} \equiv \mathrm{CH}, 3240 \mathrm{~cm}^{-1}$. The $\mathrm{N} \equiv \mathrm{C}$ - stretching mode of $\mathrm{N} \equiv \mathrm{C}-\mathrm{SH}^{52}$ and the $\mathrm{N}=\mathrm{C}=\mathrm{S}$ stretching mode of $\mathrm{HN}=$ $\mathrm{C}=\mathrm{S}^{53}$ are reported to be $2182 \mathrm{~cm}^{-1}$ and $1981.8 \mathrm{~cm}^{-1}$ in lowtemperature matrices, respectively. We detected the corresponding bands at $2186 \mathrm{~cm}^{-1}$ marked with "c" and at 1987 $\mathrm{cm}^{-1}$ marked with "d" in Fig. 10, respectively. The detection of $\mathrm{HC} \equiv \mathrm{CH}, \mathrm{N} \equiv \mathrm{C}-\mathrm{SH}$, and $\mathrm{HN}=\mathrm{C}=\mathrm{S}$ supports the photodecomposition pathway shown in Scheme 9, although it is a minor reaction pathway.

If the hydrogen atom of ${ }^{\circ} \mathrm{N}=\mathrm{CH}-\mathrm{S}^{\cdot}$ detaches but migrates neither to the sulfur atom nor to the nitrogen atom, NCS radical could be co-produced with $\mathrm{HC} \equiv \mathrm{CH}$. The band of ${ }^{\circ} \mathrm{NCS}$ radical is reported to be $1942.2 \mathrm{~cm}^{-1}$ in free jet experiment. ${ }^{54,55}$ We tried to detect the corresponding band, but there is no band in the $\mathrm{N}=\mathrm{C}=\mathrm{S}$ stretching region between 1970 and $1900 \mathrm{~cm}^{-1}$ in Fig. 10. Instead of the band due to "NCS radical, we found a band at $2046 \mathrm{~cm}^{-1}$ marked with "e" in Fig. 10, which is consistent with the band of ${ }^{\circ} \mathrm{CN}$ radical produced from $\mathrm{HC} \equiv \mathrm{N}$ by vacuum UV light in argon matrices at $14 \mathrm{~K}, 2046 \mathrm{~cm}^{-1} .^{31}$

Venkatasubramanian and Krishnamachari claimed that - NCS radical changes to ${ }^{\circ} \mathrm{CN}$ radical in a flash photolysis experiment of thiazole (1). ${ }^{9}$ Note that our difference spectra were obtained by experiments without any short-cutoff glass filters, meaning that all the radiation coming from the SHPML is used to induce photoreactions. Thus one possibility for the detection of ${ }^{\circ} \mathrm{CN}$ radical is that the photodecomposition from ${ }^{\circ} \mathrm{NCS}$ radical to $\mathrm{S}$ and ${ }^{\circ} \mathrm{CN}$ radical immediately occurs even when NCS radical is produced by detachment of the hydrogen atom from ${ }^{\circ} \mathrm{N}=\mathrm{CH}-\mathrm{S}^{\circ}$.

However, we propose another possibility that ${ }^{\circ} \mathrm{CN}$ radical is detached from the isocyano compounds, syn-(Z)-2 and (4). As explained in Section 3.5, a small amount of the cyano compounds are photoproduced from the corresponding isocyano compounds by detachment and recombination of ${ }^{\circ} \mathrm{CN}$ radical. If ${ }^{\circ} \mathrm{CN}$ radical detached from the isocyano compounds stays in a low-temperature argon-matrix cage without recombination, the IR band of ${ }^{\circ} \mathrm{CN}$ radical is detectable.

\subsection{Other minor photofragments}

There is an unassigned weak band at $2034 \mathrm{~cm}^{-1}$ marked with "f" in the $\mathrm{C} \equiv \mathrm{N}-$ stretching region of Fig. 10. The wavenumber of this band is much lower than that of the normal isocyano compounds such as syn-(Z)-2, syn-3, anti-3, and (4), implying that it is characteristic of an accumulated multiple bond like $\mathrm{HN}=\mathrm{C}=\mathrm{S}$. We tentatively assign this band to thiofulminic acid ( $\mathrm{HC} \equiv \mathrm{NS}$ ), which is an isomer of $\mathrm{HN}=\mathrm{C}=\mathrm{S}$ and $\mathrm{N} \equiv \mathrm{C}-\mathrm{SH}$. The wavenumber of the $\mathrm{N} \equiv \mathrm{C}$ - stretching mode of $\mathrm{HC} \equiv \mathrm{NS}$ is reported to be $2035 \mathrm{~cm}^{-1} .^{56}$

\section{Conclusions}

We have investigated the photolysis of thiazole (1) upon UV irradiation by a joint use of the low-temperature matrixisolation IR spectroscopy and the DFT chemical calculations. The UV-induced photoreaction pathways of thiazole (1) isolated in solid argon matrices are summarized in Scheme 10. The major ring-opening photoreactions caused by the cleavage of the $\mathrm{S} 1-\mathrm{C} 2$ bond are initially induced at early irradiation stage to produce ${ }^{\circ} \mathrm{CH}=\mathrm{N}-\mathrm{CH}=\mathrm{CH}-\mathrm{S}^{*}$ biradical. The hydrogen atom on the $\mathrm{C} 2$ atom of ${ }^{\circ} \mathrm{CH}=\mathrm{N}-\mathrm{CH}=\mathrm{CH}-\mathrm{S}^{\cdot}$ migrates to $\mathrm{S} 1$ to form syn$(Z)-2$ or to C5 to form (4), as shown in the red area of Scheme 10. Syn-(Z)-2 changes to other undetected isocyano compounds, $s y n-3$ and anti-3, in the secondary photolysis by the hydrogenatom migration from S1 to $\mathrm{C} 4$, while (4) changes to syn-3. These photoreaction pathways are supported by the kinetic analysis of the absorbance changes of IR bands against the irradiation time. When the $\mathrm{N} 3-\mathrm{C} 4$ bond cleaves following the cleavage of the $\mathrm{S} 1-\mathrm{C} 2$ bond, $\mathrm{HC} \equiv \mathrm{N}$ and ${ }^{\circ} \mathrm{CH}=\mathrm{CH}-\mathrm{S}^{\cdot}$ biradical are photodecomposed from ${ }^{\circ} \mathrm{CH}=\mathrm{N}-\mathrm{CH}=\mathrm{CH}-\mathrm{S}{ }^{\circ}$. The hydrogen atom on the center carbon atom of ${ }^{\circ} \mathrm{CH}=\mathrm{CH}-\mathrm{S}^{*}$ 


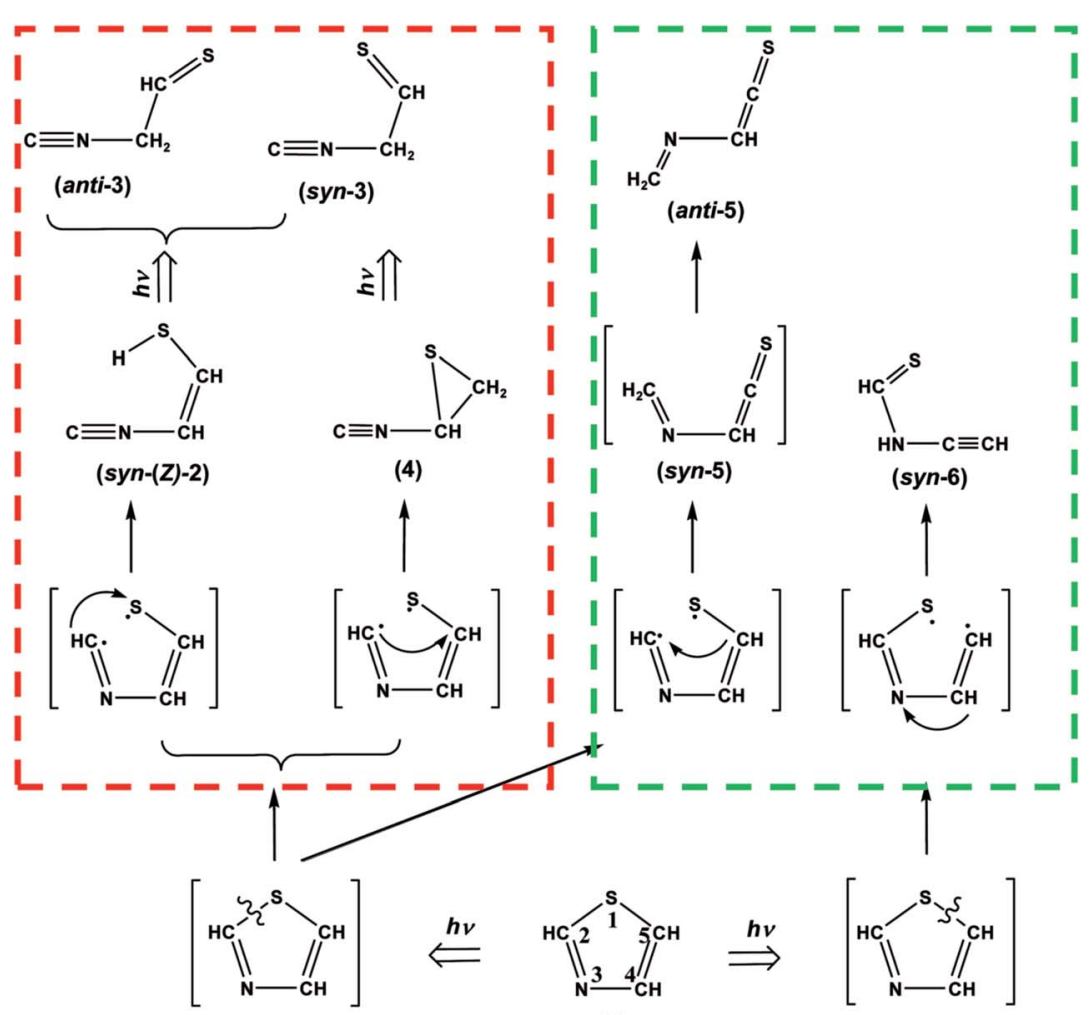

(1)
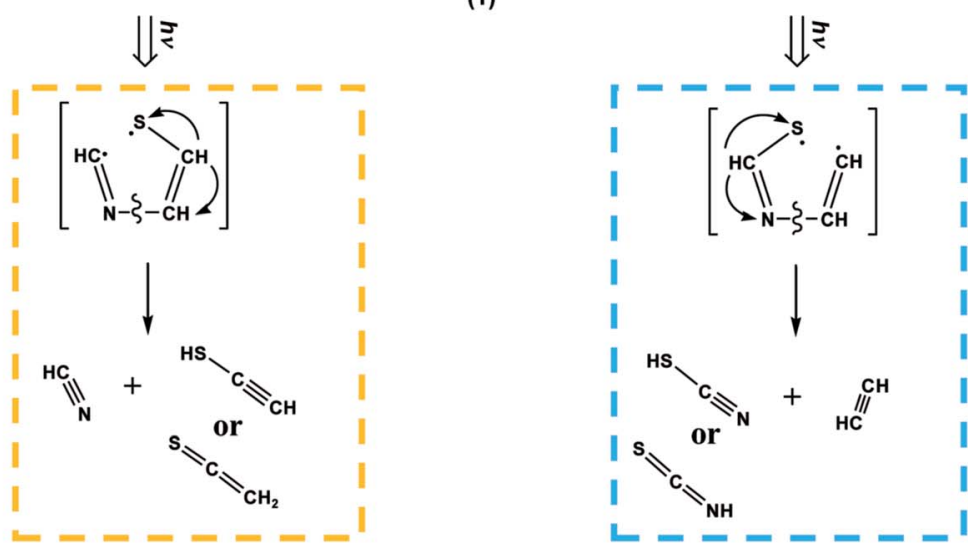

Scheme 10 Photoreaction pathways of thiazole (1).

immediately migrates to the end carbon atom to form $\mathrm{CH}_{2}=$ $\mathrm{C}=\mathrm{S}$ or to the sulfur atom to form $\mathrm{HC} \equiv \mathrm{C}-\mathrm{SH}$, as shown in the orange area of Scheme 10.

On the other hand, another minor ring-opening photoreaction is caused by the cleavage of the $\mathrm{S} 1-\mathrm{C} 2$ bond upon prolonged UV irradiation. The hydrogen-atom migration from C5 to $\mathrm{C} 2$ in ${ }^{\circ} \mathrm{CH}=\mathrm{N}-\mathrm{CH}=\mathrm{CH}-\mathrm{S}^{\circ}$ forms anti-5 via syn-5 initially produced in an argon-matrix cage, as shown in the green area of Scheme 10. Other minor ring-opening photoreaction is caused by the cleavage of the $\mathrm{C} 5-\mathrm{S} 1$ bond upon prolonged UV irradiation to produce ${ }^{\circ} \mathrm{CH}=\mathrm{CH}-\mathrm{N}=\mathrm{CH}-\mathrm{S}^{*}$ biradical, from which syn6 is produced by the hydrogen-atom migration from $\mathrm{C} 4$ to N3, where the syn conformation is kept in an argon-matrix cage without photoconversion to anti-6. The photoproducts of (2), (3), (4), (5) and (6) are identified for the first time in the present study by a joint use of IR spectroscopy and DFT calculations.
When the N3-C4 bond cleaves following the cleavage of the $\mathrm{C} 5-\mathrm{S} 1$ bond, $\mathrm{HC} \equiv \mathrm{CH}$ and ${ }^{\circ} \mathrm{N}=\mathrm{CH}-\mathrm{S}{ }^{\cdot}$ biradical are photodecomposed from ${ }^{\circ} \mathrm{CH}=\mathrm{CH}-\mathrm{N}=\mathrm{CH}-\mathrm{S}{ }^{\circ}$. The hydrogen atom of $\cdot \mathrm{N}=\mathrm{CH}-\mathrm{S}^{\cdot}$ immediately migrates to the nitrogen atom to form $\mathrm{HN}=\mathrm{C}=\mathrm{S}$ or to the sulfur atom to form $\mathrm{N} \equiv \mathrm{C}-\mathrm{SH}$, as shown in the blue area of Scheme 10. In addition, several weak bands in the difference spectra measured after prolonged UV irradiation are tentatively assigned to cyano compounds caused by photoconversion from isocyano compounds, ${ }^{\circ} \mathrm{CN}$ radical caused by detachment from isocyano compounds, and $\mathrm{HC} \equiv \mathrm{NS}$ caused by photoisomerization from photofragments such as $\mathrm{N} \equiv \mathrm{C}-\mathrm{SH}$.

In the present study, we investigated the photochemical reactivity and stability of thiazole isolated in solid argon matrices by a joint use of IR spectroscopy and DFT calculations. By examination of absorbance changes of IR bands against irradiation time, we identified intermediates and final 
products. Some of them are unknown isocyano compounds, and some of them are species interested in astrochemistry and astrophysics. We expect that the present results will contribute to develop these research fields and help to detect other simple but unknown species.

\section{Conflict of interest}

The authors declare no competing financial interest.

\section{Acknowledgements}

The authors are grateful to Prof. Igor Reva of University of Coimbra in Portugal for his valuable discussion and to emeritus Prof. Kozo Kuchitsu of the University of Tokyo in Japan for his helpful advice of English presentation. They are also grateful to Dr. Masaya Miyagawa of Chuo University for his helpful experimental supports.

\section{References}

1 Z. Jin, Nat. Prod. Rep., 2011, 28, 1143-1191.

2 Z. Jin, Nat. Prod. Rep., 2013, 30, 869-915.

3 M. V. N. de Souza, J. Sulfur Chem., 2005, 26, 429-449.

4 C. A. Cole, N. J. Demarais, Z. Yang, T. P. Snow and V. M. Bierbaum, Astrophys. J., 2013, 779, 181.

5 M. W. Powner, S.-L. Zheng and J. W. Szostak, J. Am. Chem. Soc., 2012, 134, 13889-13895.

6 M. W. Powner, B. Gerland and J. D. Sutherland, Nature, 2009, 459, 239-242.

7 A. Pawda, in Rearrangements in Ground and Excited States, Academic Press, 1980, pp. 501-549.

8 J. P. Catteau, A. Lablanche-Combier and A. Pollet, J. Chem. Soc. D, 1969, 1018.

9 R. Venkatasubramanian and S. Krishnamachari, Pramana, 1988, 30, 529-533.

10 I. Couturier-Tamburelli, B. Sessouma and J. P. Aycard, J. Mol. Struct., 2001, 560, 197-203.

11 L. Williamson and B. Meyer, Spectrochim. Acta, Part A, 1970, 26, 331-336.

12 A. Halasa, I. Reva, L. Lapinski, M. J. Nowak and R. Fausto, J. Phys. Chem. A, 2016, 120, 2078-2088.

13 M. Sekine and M. Nakata, Chem. Phys. Lett., 2011, 508, 33-37. 14 M. Miyagawa, N. Akai and M. Nakata, J. Mol. Struct., 2015, 1086, 1-7.

15 M. J. Frisch, G. W. Trucks, H. B. Schlegel, G. E. Scuseria, M. A. Robb, J. R. Cheeseman, J. A. Montgomery Jr., T. Vreven, K. N. Kudin, J. C. Burant, J. M. Millam, S. S. Iyengar, J. Tomasi, V. Barone, B. Mennucci, M. Cossi, G. Scalmani, N. Rega, G. A. Petersson, H. Nakatsuji, M. Hada, M. Ehara, K. Toyota, R. Fukuda, J. Hasegawa, M. Ishida, T. Nakajima, Y. Honda, O. Kitao, H. Nakai, M. Klene, X. Li, J. E. Knox, H. P. Hratchian, J. B. Cross, V. Bakken, C. Adamo, J. Jaramillo, R. Gomperts, R. E. Stratmann, O. Yazyev, A. J. Austin, R. Cammi, C. Pomelli, J. W. Ochterski, P. Y. Ayala, K. Morokuma, G. A. Voth, P. Salvador, J. J. Dannenberg, V. G. Zakrzewski,
S. Dapprich, A. D. Daniels, M. C. Strain, O. Farkas, D. K. Malick, A. D. Rabuck, K. Raghavachari, J. B. Foresman, J. V. Ortiz, Q. Cui, A. G. Baboul, S. Clifford, J. Cioslowski, B. B. Stefanov, G. Liu, A. Liashenko, P. Piskorz, I. Komaromi, R. L. Martin, D. J. Fox, T. Keith, M. A. Al-Laham, C. Y. Peng, A. Nanayakkara, M. Challacombe, P. M. W. Gill, B. Johnson, W. Chen, M. W. Wong, C. Gonzalez and J. A. Pople, Gaussian 03, Revision E.01, Gaussian, Inc., Wallingford CT, 2004.

16 G. Sbrana, E. Castellucci and M. Ginanneschi, Spectrochim. Acta, Part A, 1967, 23, 751-758.

17 I. Reva, M. J. Nowak, L. Lapinski and R. Fausto, Phys. Chem. Chem. Phys., 2015, 17, 4888-4898.

18 C. J. Evans, J. P. Carter, D. R. T. Appadoo, A. Wong and D. McNaughton, J. Mol. Spectrosc., 2015, 316, 32-37.

19 B. Ellis and P. J. F. Griffiths, Spectrochim. Acta, 1965, 21, 1881-1892.

20 D. Lin-Vien, N. B. Colthup, W. G. Fateley and J. G. Grasselli, in The Handbook of Infrared and Raman Characteristic Frequencies of Organic Molecules, ed. D. L.-V. B. C. G. F. G. Grasselli, Academic Press, San Diego, 1st edn, 1991, pp. 105-115.

21 G. A. McGibbon, J. Hrušák, D. J. Lavorato, H. Schwarz and J. K. Terlouw, Chem.-Eur. J., 1997, 3, 232-236.

22 W. A. Rendall, A. Clement, M. Torres and O. P. Strausz, J. Am. Chem. Soc., 1986, 108, 1691-1692.

23 C. M. Nunes, I. Reva, T. M. V. D. Pinho e Melo and R. Fausto, J. Org. Chem., 2012, 77, 8723-8732.

24 J. Miyazaki and Y. Yamada, J. Mol. Struct., 2004, 692, 145153.

25 M. D'Auria, Tetrahedron, 2002, 58, 8037-8042.

26 M.-D. Su, Phys. Chem. Chem. Phys., 2014, 16, 17030-17042.

27 J. W. Pavlik, C. R. Pandit, C. J. Samuel and A. C. Day, J. Org. Chem., 1993, 58, 3407-3410.

28 A. Lablache-Combier and A. Pollet, Tetrahedron, 1972, 28, 3141-3151.

29 S. Califano, F. Piacenti and G. Sbrana, Spectrochim. Acta, 1964, 20, 339-344.

30 T. Nakagawa and Y. Morino, Bull. Chem. Soc. Jpn., 1969, 42, 2212-2219.

31 D. E. Milligan and M. E. Jacox, J. Chem. Phys., 1967, 47, 278285.

32 C. M. King and E. R. Nixon, J. Chem. Phys., 1968, 48, 16851695.

33 J. Pacansky and G. V. Calder, J. Phys. Chem., 1972, 76, 454456.

34 A. D. Abbate and C. B. Moore, J. Chem. Phys., 1985, 82, 12551262.

35 K. Satoshi, M. Takayanagi and M. Nakata, J. Mol. Struct., 1997, 413-414, 365-369.

36 E. Suzuki and F. Watari, Chem. Phys. Lett., 1990, 168, 1-4.

37 R. Schulz and A. Schweig, Z. Naturforsch., B: Anorg. Chem., Org. Chem., 1984, 39, 1536-1540.

38 V. A. Korolev and E. G. Baskir, Russ. Chem. Bull., 1995, 44, 448-454.

39 E. Briard, J. Levillain, J.-L. Ripoll, Y. Dat, A. Marcual and C. Lange, Eur. J. Org. Chem., 1999, 1999, 869-874. 
40 A. Krantz and J. Laureni, J. Am. Chem. Soc., 1981, 103, 486496.

41 K. B. Wiberg and R. E. Rosenberg, J. Am. Chem. Soc., 1990, 112, 1509-1519.

42 K. Kuchitsu, T. Fukuyama and Y. Morino, J. Mol. Struct., 1968, 1, 463-479.

43 J. A. Beukes, P. Klaeboe, H. Møllendal and C. J. Nielsen, J. Raman Spectrosc., 1995, 26, 799-812.

44 A. Bénidar, R. Georges, J.-C. Guillemin, O. Mó and M. Yáñez, J. Phys. Chem. A, 2010, 114, 9583-9588.

45 A. Luna, O. Mó, M. Yáñez, J.-C. Guillemin, J.-F. Gal and P.-C. Maria, Int. J. Mass Spectrom., 2007, 267, 125-133.

46 G. A. Ozin, D. F. McIntosh, W. J. Power and R. P. Messmer, Inorg. Chem., 1981, 20, 1782-1792.

47 A. Engdahl and B. Nelander, Chem. Phys. Lett., 1983, 100, 129-132.

48 E. S. Kline, Z. H. Kafafi, R. H. Hauge and J. L. Margrave, J. Am. Chem. Soc., 1985, 107, 7559-7562.
49 E. S. Kline, Z. H. Kafafi, R. H. Hauge and J. L. Margrave, J. Am. Chem. Soc., 1987, 109, 2402-2409.

50 A. V. Golovkin, D. I. Davlyatshin, A. L. Serebrennikova and L. V. Serebrennikov, J. Mol. Struct., 2013, 1049, 392-399.

51 G. Herzberg, Molecular spectra and molecular structure II.: Infrared and Raman spectra of polyatomic molecules, Van Nostrand Reinhold, 1945.

52 M. Wierzejewska and Z. Mielke, Chem. Phys. Lett., 2001, 349, 227-234.

53 M. Wierzejewska and R. Wieczorek, Chem. Phys., 2003, 287, 169-181.

54 M. E. Jacox, J. Phys. Chem. Ref. Data, 2003, 32, 1-441.

55 F. J. Northrup and T. J. Sears, J. Chem. Phys., 1989, 91, 762774.

56 T. Pasinszki, M. Krebsz, G. Bazsó and G. Tarczay, Chem.-Eur. J., 2009, 15, 6100-6102. 